\title{
An Improved Model Predictive Control Method for Three-Port Soft Open Point
}

\author{
Zhengqi Wang $\mathbb{D}^{1}{ }^{1}$ Liusen Sheng, ${ }^{1}$ Qunhai Huo, ${ }^{2}$ and Sipeng Hao ${ }^{1}$ \\ ${ }^{1}$ School of Electric Power Engineering, Nanjing Institute of Technology, Nanjing 211167, China \\ ${ }^{2}$ Institute of Electrical Engineering, Chinese Academy of Sciences, Beijing 100190, China \\ Correspondence should be addressed to Zhengqi Wang; wzqnjit@163.com
}

Received 26 March 2021; Revised 9 June 2021; Accepted 15 June 2021; Published 29 June 2021

Academic Editor: Qiuye Sun

Copyright ( 92021 Zhengqi Wang et al. This is an open access article distributed under the Creative Commons Attribution License, which permits unrestricted use, distribution, and reproduction in any medium, provided the original work is properly cited.

Soft open point (SOP) is a key power electronic device to improve the flexibility and stability of the distribution network and is becoming a research hotspot. The traditional double closed-loop control of SOP has a complex structure, difficult process of parameter design, and poor output power quality. To solve these problems, finite control set model predictive control (FCS-MPC) has been adopted. Since FCS-MPC involves a large amount of calculation and experiences delay in current tracking, an improved FCS-MPC with delay compensation is proposed for three-port SOP in this paper to replace the inner loop current control strategy. Improved model predictive control combines the two-step prediction method based on the voltage vector and vector angle compensation method. The vector method is used to construct a mathematical model and a prediction model of three-port SOP. Based on FCS-MPC, the two-step prediction method that takes voltage as the target is used to compensate for the current delay problem, and the amount of calculation is reduced by converting the control target. Meanwhile, the vector angle compensation method is used to compensate the future reference value. Finally, a simulation model is built in MATLAB/Simulink. The simulation results under steady state and dynamic conditions show that the proposed strategy can effectively improve the current delay and reduce the amount of calculation. Furthermore, it has better current tracking accuracy and faster dynamic response speed.

\section{Introduction}

With the increasing application of new energy such as wind energy and solar energy, the penetration rate of renewable distributed energy in the distribution network is getting higher and higher $[1,2]$. Additionally, with the large-scale access of new loads represented by electric vehicles, the power flow of the power grid is becoming more and more complicated, and power quality problems, such as voltage crossing the line, are becoming more and more prominent. These problems have seriously affected the stability and safety of the distribution network $[3,4]$. The original adjustment methods of the distribution network have limited control accuracy and adjustment speed, which has restricted the improvement of the control ability of the distribution network. Therefore, to further improve the flexibility and reliability of the operation of the distribution network, the development of power electronic equipment for the distribution network has attracted the attention of scholars from all over the world. Soft open point (SOP) is a new type of power electronic device that can replace the traditional contact switch, which is becoming a research hotspot $[5,6]$. SOP cannot only solve the shortcomings of the traditional contact switch that it only has two states and a limited number of switches but also it has the function of regulating the flow and the characteristics of various control methods. Many scholars have done in-depth research on SOP, including optimization planning [7-9], operation scheduling $[10,11]$, and fault recovery $[12,13]$. However, there is little research on the control strategy of SOP itself. Ouyang et al. proposed a three-port SOP based on a power electronic transformer and studied its DC voltage control strategy [14]. Hou et al. adopted a double closed-loop control strategy [15], but for a three-port SOP, a double closed-loop control 
strategy requires a total of 12 proportional-integral (PI) regulators, resulting in a complex control structure and difficult parameter adjustment, which can lead to low current tracking accuracy and slow dynamic response. Li et al. used the compound control of feedback linearization control and sliding mode control to replace the current inner loop in order to reduce the PI parameters, but the sliding mode controller parameters were difficult to design [16].

With the development of the microprocessor, finite control set model predictive control (FCS-MPC) has been applied more and more often to power electronic systems. Its advantages include intuitive principle, easy modeling, and no complex parameter design. It also has a very good effect on overcoming the nonlinearity and uncertainty in the industrial control process. FCS-MPC is widely used in inverters, rectifiers, permanent magnet synchronous machine, and modular multilevel converters [17-23], but rarely in the three-port SOP. Peng et al. proposed a three-port SOP coordinated control strategy based on FCS-MPC [24]. Although FCS-MPC has a faster dynamic response speed and better output power quality, it also has some problems such as a large amount of calculation and delay in current prediction. To solve the above problems, an improved model predictive control strategy based on three-port SOP is proposed, which can replace the inner loop current control of double closed-loop control. By reducing the amount of calculation and increasing the delay compensation and future reference compensation, the proposed strategy further reduces the problem of the current delay, improves the current tracking accuracy, and ensures faster dynamic response speed. The main contributions of this paper are as follows:

(1) In order to realize the decoupling control of the system, the mathematical model of three-port SOP is established by the vector method and the $d q$ coordinate transformation method.

(2) The two-step prediction method based on the voltage vector and the vector angle compensation method are combined to improve FCS-MPC, which can further improve the control performance. Usually, the two-step prediction method takes the current as the target, but this article adopts the two-step prediction method that takes voltage as the target, which can reduce the amount of calculation. Meanwhile, the vector angle compensation method is used to compensate the future reference value lag, including the compensation of reference current and reference voltage.

(3) Improved model predictive control is applied to three-port SOP for the first time. By using the improved FCS-MPC to replace the inner loop current control with double closed-loop control, the complex parameter design process of the proportional-integral (PI) regulator can be omitted, and the dynamic response speed and steady-state tracking accuracy of the current can be effectively improved.

The rest of the article is arranged as follows: Section 2 establishes the mathematical model of the three-port SOP. Section 3 analyzes the control principle of the improved FCS-MPC and designs the overall control scheme of the system. Section 4 simulates and analyzes the proposed control scheme through MATLAB/Simulink. Section 5 concludes the paper with a discussion of the results.

\section{Three-Port SOP Mathematical Model}

The two-port SOP composed of two voltage source converters (VSCs) has limitations in the form of access in the distribution network, as it cannot realize the flexible interconnection of multiple ports. Hence, this paper takes the three-port SOP as the research object to establish the mathematical model of the three-port SOP. As shown in Figure 1, the three-port SOP is connected by three VSCs through DC side capacitors, and it is usually connected at the end of the distribution network to connect the three different feeders.

The main circuit structure of the three-port SOP is shown in Figure 2. The subscript $j=1,2$, and 3, representing port 1 , port 2 , and port 3 . The subscripts $a, b$, and $c$ denote phase $a$, phase $b$, and phase $c . E_{j a}, E_{j b}$, and $E_{j c}$ indicate the $a$, $b$, and $c$ phase grid voltages of port $j . U_{j a N}, U_{j b N}$, and $U_{j c N}$ represent the voltages of port $j$ of VSC relative to point $N$ in the figure; hence, they are the output voltages of the inverter. $R_{j}$ represents the equivalent resistance of the $j$ port line, $L_{j}$ represents the $j$ port filter reactor, $C$ represents $D C$ side capacitance, and $i d c j$ represents the current on the DC side of the $j$ port VSC.

The three-port SOP switch states are defined as follows:

$$
S k=\left\{\begin{array}{ll}
1, & \begin{array}{l}
\text { if } k \text { - phase upper bridge arm is turned on } \\
\text { and lower bridge arm is turned off. }
\end{array} \\
0, & \text { if } k \text { - phase lower bridge arm is turned on } \\
\text { and upper bridge arm is turned off. }
\end{array} \quad(k=a, b, \text { and } c) .\right.
$$

The output voltage of each port is represented by the switch states:

$$
U_{j k N}=S_{j k} \cdot U_{d c}, \quad k=a, b, \text { and } c
$$

where $S_{j k}$ is $j$ port switch states and $U_{d c}$ is AC side voltage. Since the unit vector $\alpha=e^{j 2 \pi / 3}=(-1+j \sqrt{3}) / 2$ represents the phase difference of $120^{\circ}$, the output voltage vector of each port can be defined as 


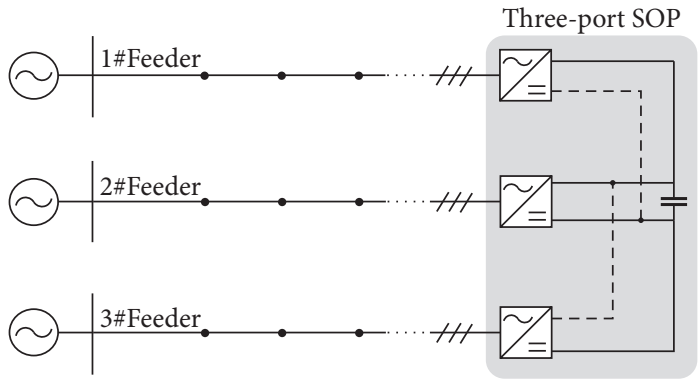

FIGURE 1: Location of three-port SOP in the distribution network.

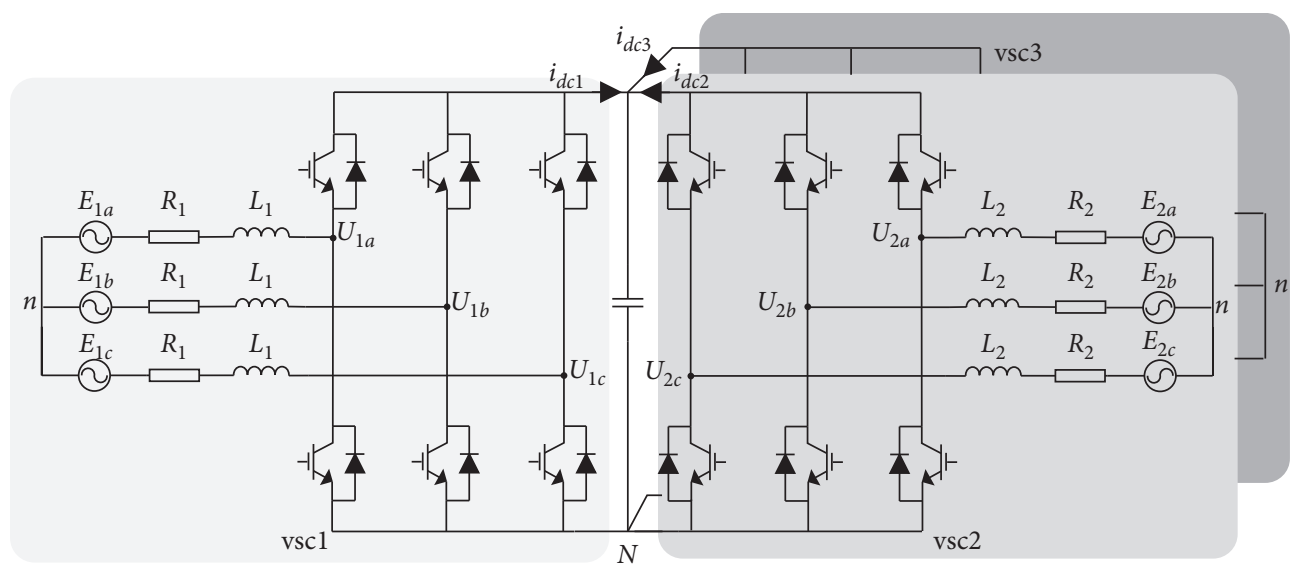

Figure 2: The main circuit structure of the three-port SOP.

$$
U_{j}=\frac{2}{3}\left(U_{j a N}+\alpha U_{j b N}+\alpha^{2} U_{j c N}\right)
$$

where $U_{j a N}, U_{j b N}$, and $U_{j c N}$ represent the voltages of port $j$ of VSC relative to point $N$.

Assuming that the direction of the reference current is shown in Figure 2, the dynamic equation on the AC side of the three-port SOP is as follows:

$$
\left\{\begin{array}{l}
U_{j a N}=L_{j} \frac{\mathrm{d} i_{j a}}{\mathrm{~d} t}+R_{j} i_{j a}-E_{j a}+U_{n N} \\
U_{j b N}=L_{j} \frac{\mathrm{d} i_{j b}}{\mathrm{~d} t}+R_{j} i_{j b}-E_{j b}+U_{n N} \\
U_{j c N}=L_{j} \frac{\mathrm{d} i_{j c}}{\mathrm{~d} t}+R_{j} i_{j c}-E_{j c}+U_{n N},
\end{array}\right.
$$

where $i_{j a}, i_{j b}$, and $i_{j c}$ are the three-phase load currents of port $j, E_{j a}, E_{j a}$, and $E_{j a}$ are $a, b$, and $c$ phase grid voltage of port $j$, respectively, and $U_{n N}$ is the voltage of neutral point $n$ to $N$ point.

Substituting (4) into (3),

$$
\begin{aligned}
U j= & L \frac{\mathrm{d}}{\mathrm{d} t}\left(\frac{2}{3}\left(i_{j a}+\alpha i_{j b}+\alpha^{2} i_{j c}\right)\right)+R\left(\frac{2}{3}\left(i_{j a}+\alpha i_{j b}+\alpha^{2} i_{j c}\right)\right) \\
& +\frac{2}{3}\left(E_{j a}+\alpha E_{j b}+\alpha^{2} E_{j c}\right)+\frac{2}{3}\left(U_{n N}+\alpha U_{n N}+\alpha^{2} U_{n N}\right) .
\end{aligned}
$$

According to the definition mode of the output voltage vector of (4), the load current vector and the grid voltage vector are defined as

$$
\left\{\begin{array}{l}
i_{j}=\frac{2}{3}\left(i_{j a}+\alpha i_{j b}+\alpha^{2} i_{j c}\right), \\
E_{j}=\frac{2}{3}\left(E_{j a}+\alpha E_{j b}+\alpha^{2} E_{j c}\right) .
\end{array}\right.
$$

Because $\quad(2 / 3)\left(U_{n N}+\alpha U_{n N}+\alpha^{2} U_{n N}\right)=(2 / 3)(1+\alpha$ $\left.+\alpha^{2}\right) U_{n N}=0$, the vector form of the AC-side dynamic equation of the three-port SOP is as follows:

$$
U_{j}=L \frac{\mathrm{d} i_{j}}{\mathrm{~d} t}+R_{j} i_{j}-E_{j}
$$

The dynamic equation of DC side voltage is as follows: 


$$
C \frac{\mathrm{d} u_{d c}}{\mathrm{~d} t}=i_{d c 1}+i_{d c 2}+i_{d c 3}=\sum_{j=1}^{3} m_{j a} i_{j a}+m_{j b} i_{j b}+m_{j c} i_{j c}
$$

where $U_{d c}$ is the DC side bus voltage, $i_{d c 1}, i_{d c 2}$, and $i_{d c 3}$ represent the current on the DC side of port 1, port 2, and port 3, respectively, and $m_{j a}, m_{j b}$, and $m_{j c}$ are the switching functions, and the switching states can be defined as

$$
\left\{\begin{array}{l}
m_{j a}=s_{a}-\frac{s_{a}+s_{b}+s_{c}}{3}, \\
m_{j b}=s_{b}-\frac{s_{a}+s_{b}+s_{c}}{3} \\
m_{j c}=s_{c}-\frac{s_{a}+s_{b}+s_{c}}{3}
\end{array}\right.
$$

where $s_{a}, s_{b}$, and $s_{c}$ are the switch states of $a, b$, and $c$ phases, respectively.

If all the devices in the three-port SOP are ideal components,

$$
P_{1}+P_{2}+P_{3}=U_{d c} \sum_{j=1}^{3} m_{j a} i_{j a}+m_{j b} i_{j b}+m_{j c} i_{j c} .
$$

Substituting (8) into (10),

$$
\sum_{j=1}^{3} P_{j}=U_{d c} \sum_{j=1}^{3} i_{d c j}=U_{d c} C \frac{\mathrm{d} u_{d c}}{\mathrm{~d} t} .
$$

When the system is in a steady state, the DC side voltage remains stable and the rate of DC voltage change is zero. At this time, $\sum_{j=1}^{3} P_{j}=0$. That is to say, when the loss of SOP is ignored, the input and output active power of each port are conserved in the steady-state operation.

According to the instantaneous power theory, the instantaneous power expression of each port is as follows:

$$
\left\{\begin{array}{l}
P_{j}=E_{j d} i_{j d}+E_{j q} i_{j q} \\
Q_{j}=E_{j q} i_{j d}-E_{j d} i_{j q}
\end{array}\right.
$$

where $P_{j}$ and $Q_{j}$ are the active and reactive power output of port $j, i_{j d}$ and $i_{j q}$ are the components of three-phase load output current on the $d$-axis and $q$-axis, respectively, and $E_{j d}$ and $E_{j q}$ are the components of grid voltage on the $d$-axis and $q$-axis of port $j$, respectively.

Under the condition of three-phase grid voltage balance, the $d$-axis of the $d q$ coordinate system is oriented to the direction of the grid voltage synthesis vector $E_{j}$ by using the grid voltage vector oriented control. We can obtain $E_{j q}=0$, and $E_{j d}$ is constant. Thus, (12) can be changed into

$$
\left\{\begin{array}{l}
P_{j}=\frac{3}{2} E_{j d} i_{j d}, \\
Q_{j}=-\frac{3}{2} E_{j d} i_{j q} .
\end{array}\right.
$$

It can be seen from (13) that there is a linear relationship between the power of each port and the component of the current on the $d$-axis and $q$-axis, respectively. By controlling $i_{j d}$ and $i_{j q}$, the active power and reactive power of each port of the three-port SOP can be independently controlled, so the power decoupling control is realized.

\section{Control of Three-Port SOP}

3.1. Traditional FCS-MPC and Its Delay Compensation Method. The traditional FCS-MPC takes the current as the target to predict. The prediction current corresponding to each voltage vector is predicted by the prediction model. The predicted current is compared with the reference current, and then, the predicted current value closest to the reference current is selected by the cost function. The switching state corresponding to the predicted current is applied to the SOP. Assuming that the sampling interval is $T_{s}$, after discretizing (7), the expression of the predicted current vector for each port can be obtained as follows:

$$
i_{j}^{p}(k+1)=\left(1-\frac{R_{j} T_{s}}{L_{j}}\right) i_{j}(k)+\frac{T_{s}}{L_{j}}\left(U_{j}(k)-E_{j}(k)\right),
$$

where $i_{j}^{p}(k+1)$ is the predicted current vector value for port $j$ at time $k+1, i_{j}(k)$ represents the output current vector of port $j$ at time $k, E_{j}(k)$ represents the power network voltage vector of port $j$ at time $k$, and $U_{j}(k)$ represents the output voltage vector of the port $j$ at time $k$. Each port VSC can generate seven different voltage vectors according to eight different switch states. According to (3), the voltage vectors are shown in Table 1.

The traditional FCS-MPC does not consider the system delay, but in the actual system, there is a periodic delay in the control system because of the sample delay, the long execution time of the algorithm, the switch action delay, and so on. As shown in Figure 3, without considering the delay compensation, the system uses the voltage vector $U_{j}(k)$ of the current moment to predict the predicted current $i_{j}^{p}(k+1)$ of the next moment. However, because it takes a certain time to calculate the optimal voltage vector at the current time, which is longer than the sampling interval, the selected voltage vector cannot act on time $k$ immediately. It can only act on time $k+1$, which leads to the one-beat delay. Due to the existence of calculation delay, the system can only predict $i_{j}^{p}(k+1)$ (rather than $\left.i_{j}^{p}(k+2)\right)$ and act at time $k+2$. This causes a big deviation between the predicted current and the actual current, deteriorates system performance, and increases the current ripple. Therefore, it is necessary to compensate for the time delay of the control system.

As shown in Figure 4, although it is impossible to predict $i_{j}^{p}(k+1)$ at time $k$ immediately after adding delay compensation, the predicted current value at time $k\left(i_{j}^{p}(k+1)\right)$ can be calculated first during the calculation time. The predicted current $i_{j}^{p}(k+2)$ can be calculated by using $i_{j}^{p}(k+$ 1 ) at time $k+1$, and the optimal voltage vector can also be selected. After the completion of the calculation, it is possible to apply the voltage vector $U_{j}(k+1)$ to the control system at 
TABLE 1: Switching states and voltage vectors.

\begin{tabular}{lllc}
\hline$S_{a}$ & $S_{b}$ & $S_{c}$ & Voltage vector $U_{j}$ \\
\hline 0 & 0 & 0 & $U_{j 0}=0$ \\
1 & 0 & 0 & $U_{j 1}=(2 / 3) U_{d c}$ \\
1 & 1 & 0 & $U_{j 2}=(1 / 3) U_{d c}+j(\sqrt{3} / 3) U_{d c}$ \\
0 & 1 & 0 & $U_{j 3}=-(1 / 3) U_{d c}+j(\sqrt{3} / 3) U_{d c}$ \\
0 & 1 & 1 & $U_{j 4}=-(2 / 3) U_{d c}$ \\
0 & 0 & 1 & $U_{j 5}=-(1 / 3) U_{d c}-j(\sqrt{3} / 3) U_{d c}$ \\
1 & 0 & 1 & $U_{j 6}=(1 / 3) U_{d c}-j(\sqrt{3} / 3) U_{d c}$ \\
1 & 1 & 1 & $U_{j 7}=0$ \\
\hline
\end{tabular}

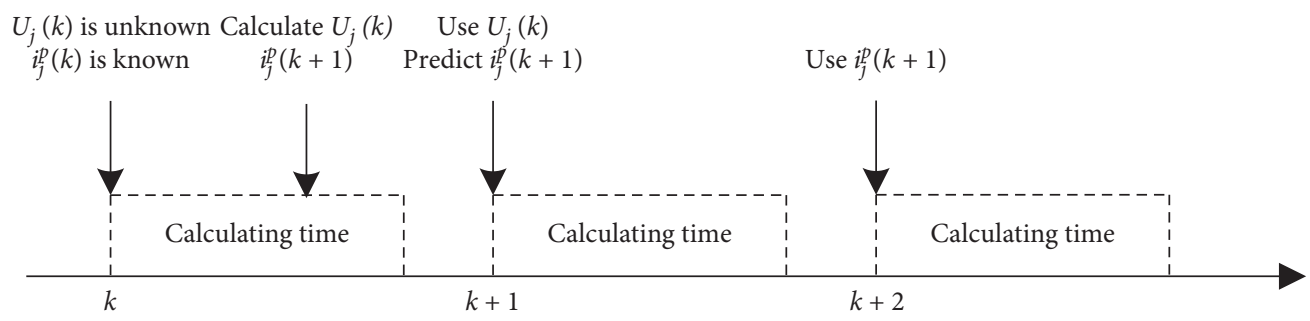

FIGURE 3: FCS-MPC without delay compensation.

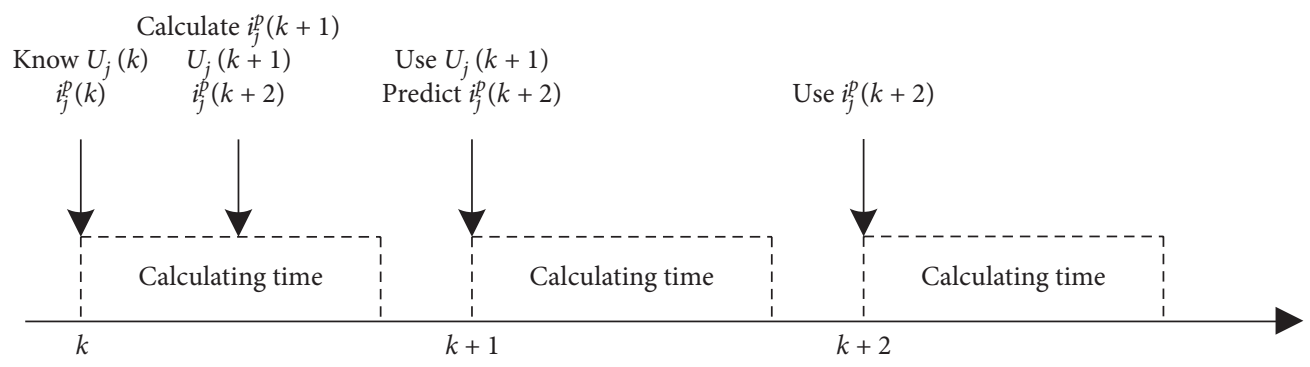

FIGURE 4: FCS-MPC considering delay compensation.

time $k+1$, and $i_{j}^{p}(k+2)$ can be predicted at time $k+1$ and applied to time $k+2$.

According to (14), after adding delay compensation, the expression of the predicted current vector is

$$
i_{j}^{p}(k+2)=\left(1-\frac{R_{j} T_{s}}{L_{j}}\right) i_{j}^{p}(k+1)+\frac{T_{s}}{L_{j}}\left(U_{j}(k+1)-E_{j}(k+1)\right),
$$

where $i_{j}^{p}(k+1)$ can be calculated by $(14), E_{j}(k+1)$ represents the voltage vector of port $j$ at time $k+1$, and $U_{j}(k+1)$ is the VSC output voltage vector of the port $j$ at time $k+1$.

The vector expression of the cost function is

$$
g_{j}=\left(i_{j}^{p}(k+2)-i_{\text {ref }}(k+2)\right)^{2},
$$

where $i_{\text {jref }}(k+2)$ is the reference current vector of $k+2$. Because the sampling frequency is higher than the reference signal frequency, it can be considered that $i_{\text {jref }}(k+2)=i_{\text {jref }}$ (k).
3.2. Improved FCS-MPC and Its Delay Compensation Method. Although FCS-MPC's delay compensation method solves the problem of delay in the process of operation, it greatly increases the amount of computation, which makes the running speed of the overall control system slower and increases the computational burden of the processor in practical applications. To reduce the amount of computation of the control system and improve the running speed of the system, the delay compensation method needs to be optimized.

It can be seen from (15) that, in order to obtain the current prediction value $i_{j}^{p}(k+2)$, optimal voltage vector $U_{j}$ $(k+1)$ must be selected by calculating (16), and then, the predicted value is calculated. If the predicted value $i_{j}^{p}(k+2)$ of $k+2$ is equal to the reference value $i_{\text {jref }}(k+2)$, the reference value of the voltage vector $U_{\text {jref }}(k+1)$ can be obtained. The reference value of this voltage is compared with eight voltage vectors (as shown in Table 1) by a new cost function, which can select the optimal voltage vector and its corresponding switching state. 
Equation (15) is transformed to obtain the vector expression of the voltage reference value:

$$
\begin{aligned}
U_{\text {jref }}(k+1)= & \frac{L_{j}}{R_{j}}\left(i_{\text {jref }}(k+2)-i_{j}^{p}(k+1)\right) \\
& +E_{j}(k+1)+R i_{j}^{p}(k+1) .
\end{aligned}
$$

Since the vector expression cannot be calculated directly in the actual control system, this expression is converted to the $d q$ coordinate system:

$$
\left\{\begin{array}{l}
U_{j d \mathrm{ref}}(k+1)=\frac{L_{j}}{R_{j}}\left(i_{j d \mathrm{ref}}(k+2)-i_{j d}^{p}(k+1)\right) \\
+E_{j d}(k+1)+R i_{j d}^{p}(k+1), \\
U_{j q \mathrm{ref}}(k+1)=\frac{L_{j}}{R_{j}}\left(i_{j q \mathrm{ref}}(k+2)-i_{j q}^{p}(k+1)\right) \\
+E_{j q}(k+1)+R i_{j q}^{p}(k+1),
\end{array}\right.
$$

where $U_{j d r e f}(k+1)$ and $U_{j q r e f}(k+1)$ are the components of the reference voltage in the $d q$ coordinate system, $i_{j d \text { ref }}(k+2)$ and $i_{\text {jqref }}(k+2)$ are the components of the reference current at time $k+2$ in the $d q$ coordinate system, $E_{j d}(k+1)$ and $E_{j q}$ $(k+1)$ are the components of the grid voltage in the $d q$ coordinate system at time $k+1$, and $i_{j d}^{p}(k+1)$ and $i_{j q}^{p}(k+1)$ are the components of the predicted values of $k+1$ in the $d q$ coordinate system.

Accordingly, a new cost function is constructed:

$$
\begin{aligned}
G_{j}= & \left(U_{j d \text { ref }}(k+1)-U_{j d}(k+1)\right)^{2} \\
& +\left(U_{j q r e f}(k+1)-U_{j q}(k+1)\right)^{2},
\end{aligned}
$$

where $U_{j d}(k+1)$ and $U_{j q}(k+1)$ are the components of the output voltage vector of the port $j$ in the $d q$ coordinate system. Since there are eight voltage vectors, their components in the $d q$ coordinate system $\left(U_{j d}(k+1)\right.$ and $\left.U_{j q}(k+1)\right)$ should also have eight each.

Figure 5 depicts the principle of selecting the optimal voltage vector. Assume that the reference voltage vector $U_{j \mathrm{ref}}$ calculated by (17) is at the position shown in the figure, the errors between the reference voltage vector $U_{\text {jref }}$ and all nonzero voltage vectors are expressed by $\Delta U_{1}$ through $\Delta U_{6}$, and the error with the zero vector is $U_{\text {jref }}$. Then, we can see intuitively that the length of $\Delta U_{1}$ is the smallest, which shows that the error between the reference voltage vectors $U_{\text {jref }}$ and $U_{j 1}$ is the smallest. $U_{j 1}$ is the optimal voltage vector, and the switching state (100) corresponding to $U_{j 1}$ is the optimal switching state.

It is worth noting that switching states (000) and (111) can both generate zero voltage vectors when the zero voltage vector is selected as the optimal voltage vector. One of the switching states in (000) and (111) should be selected according to the principle of the minimum switching frequency. If the previous switch state is (100), the current

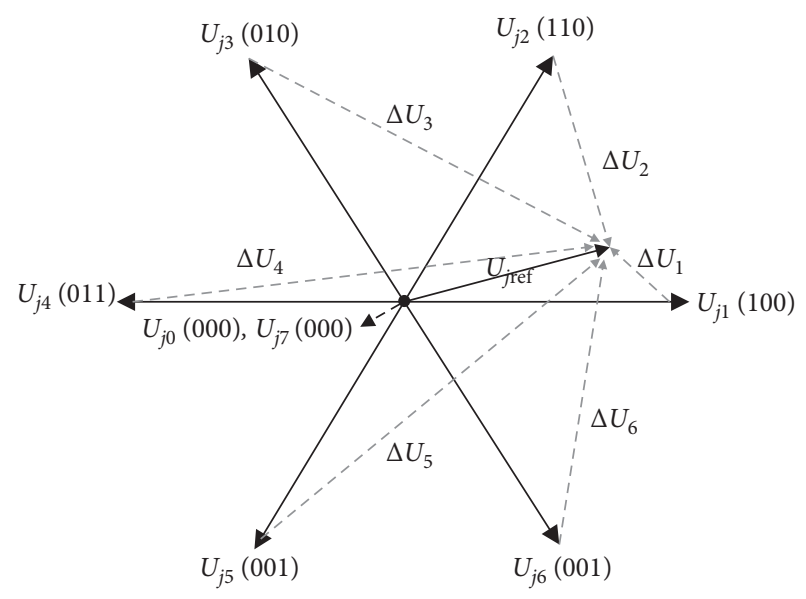

FIGURE 5: Voltage vector selection.

switch state should be selected as (000). If the previous switch state is (110), the current switch state should be selected as (111).

By comparing the traditional delay compensation method with the improved delay compensation method, it can be seen that the traditional delay compensation method needs to substitute 8 output voltage vectors into (15), and then, 8 current prediction values are obtained through 8 operations. The eight predicted current values are substituted into (16), and after 8 operations, the optimal voltage vector is obtained. Therefore, a total of 16 operations are performed in one cycle. The improved delay compensation method only needs to perform one operation on (17) to obtain the reference voltage vector, and then, by comparing the reference voltage vector with 8 output voltage vectors, the optimal voltage vector can be obtained. Therefore, only 9 operations are required in one cycle, and the amount of calculation is significantly reduced.

3.3. Future Reference Value Compensation. The above methods assume that the future reference value is the same as the current reference value. For example, in (16)-(18), the current reference value $i_{\text {jref }}(k+2)$ is approximated to the time $k$ reference value $i_{\text {jref }}(k)$. However, when the reference signal is sinusoidal, there will be a delay in the predictive current tracking reference current, which will affect the current tracking accuracy and make the control effect worse. Therefore, it is necessary to compensate for the future reference value. In this paper, the vector angle compensation method is used to compensate for the future reference value.

The future reference value can be estimated according to the change of the vector angle of a sampling time. Because the reference current $i_{\text {jref }}(k)$ is expressed as a vector, it can be expressed in the form of amplitude $I_{\text {jref }}(k)$ and phase angle $\theta$ :

$$
i_{\text {jref }}(k)=I_{\text {jref }}(k) e^{j \theta(k)} .
$$

In the steady state, if the current vector rotates at an angular velocity $\omega$ and the amplitude remains constant, the reference current phase angle at time $k+1$ is 


$$
\theta(k+1)=\theta(k)+\omega T_{s},
$$

where $\theta(k)$ is the reference current phase angle at time $k$ and $\omega T_{s}$ represents the angle that the vector has rotated in a sampling interval.

The reference current at time $k+1$ can be obtained by replacing (20) with (21):

$$
i_{\text {jref }}(k+1)=I_{\text {jref }}(k) e^{j \theta(k+1)}=I_{\text {jref }}(k) e^{j \theta(k)} e^{j \omega T_{s}} .
$$

Substitute (20) into (22) to get

$$
i_{\text {jref }}(k+1)=i_{\text {jref }}(k) e^{j \omega T_{s}} \text {. }
$$

In the same way, the grid side voltage of $k+1$ is as follows:

$$
E_{j}(k+1)=E_{j}(k) e^{j \omega T_{s}} .
$$

The current reference value of $k+2$ is

$$
i_{\text {jref }}(k+2)=i_{\text {jref }}(k) e^{j 2 \omega T_{s}} .
$$

3.4. Stability Analysis. Take port 1 as an example, the stability of SOP is analyzed, and other port analysis methods are the same. Port 1 is equivalent to the Thevenin equivalent circuit in the synchronous rotating coordinate system $(d q$ axis), as shown in Figure 6.

In the figure, $V_{s}, i_{s}$, and $Z_{s}$ are the voltage, current, and impedance on the AC side, respectively. $V_{l}, i_{l}$, and $Z_{l}$ are the voltage, current, and impedance on the DC side, respectively. $Z_{s}$ and $Z_{l}$ are $2 \times 2$ matrices under the $d q$ axis. $V_{s}, i_{s}, V_{l}$, and $i_{l}$ are $2 \times 1$ vectors [25]. Then, the output voltage is

$$
V_{p}=\frac{Z_{l}}{Z_{S}+Z_{l}} V_{S}+\frac{Z_{S}}{Z_{S}+Z_{l}} V_{l}=\frac{V_{S}+Z_{S} Y_{l} V_{l}}{E+Z_{S} Y_{l}},
$$

and the return-ratio matrix is defined as follows:

$$
T=Z_{s} Y_{l}
$$

where $E$ represents the identity matrix, and $Y_{l}=Z_{l}^{-1}$. So if and only if $E+Z_{S} Y_{l}$ has no right pole, the system is stable. In other words, the necessary and sufficient condition for system stability is that the Nyquist curve of the return-ratio matrix does not enclose the $\left(-1, j_{0}\right)$ point. According to this concept, the stability of the system is guaranteed when the eigenvalues $\left(\lambda_{T i}\right.$ and $i=1$ and 2$)$ of the return-ratio matrix are outside a certain forbidden region. As shown in Figure 7, a new type of the prohibited area is adopted [26]. The criteria are as follows:

$$
\begin{gathered}
\left|\arg \left(\lambda_{T i}\right)\right| \leq 180^{\circ}-\theta_{\mathrm{PM}}, \\
\operatorname{Re}\left(\lambda_{T i}\right) \geq-\varepsilon_{\mathrm{GM}} .
\end{gathered}
$$

$A$ is maintained outside the prohibited area to achieve system stability by using the phase margin $\left(\theta_{\mathrm{PM}}\right)$ and gain $\operatorname{margin}\left(-\varepsilon_{\mathrm{GM}}\right)$.

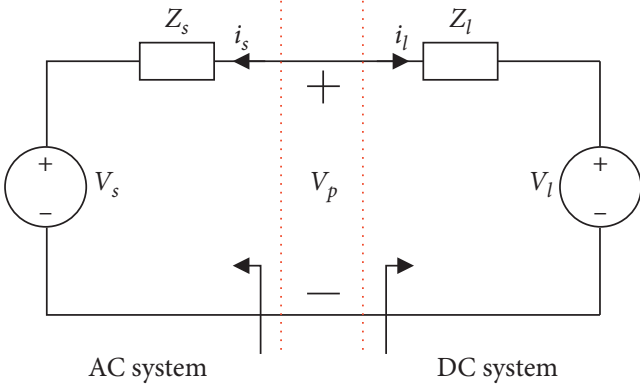

FIgUre 6: Thevenin equivalent system model.

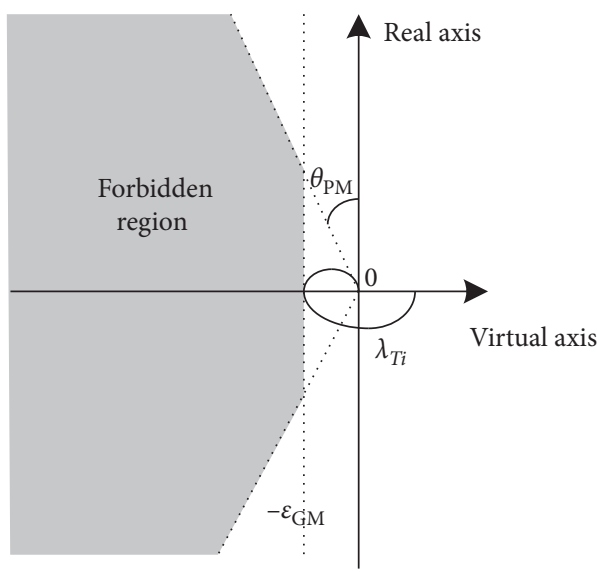

Figure 7: Novel eigenvalue forbidden region of the return-ratio matrix.

\section{Overall Control Scheme Design of the System}

It can be seen from (11) that, in normal operation, in order to ensure the stability of power transmission, it is necessary to keep the DC side voltage stable in the control of one port and ensure that the power is controllable in the other two ports. Meanwhile, the reactive power of each port can be controlled without the participation of DC voltage.

Based on the above analysis, VSC1 is selected as the rectifier side. VSC2 and VSC3 are selected as the inverter side to design the overall control scheme. The outer loop control scheme of VSC1 is constant DC voltage and reactive power mode ( $U_{d c} Q$ control). The outer loop control of VSC2 and VSC3 is constant active power and reactive power control mode (PQ control). Their inner loop control modes are all improved FCS-MPC with delay compensation. The purpose of the outer loop control is to provide the current reference value for the inner loop control, and the purpose of the inner loop control is to provide the switch signal for the VSC of each port.

4.1. $U_{d c} Q$ Control Mode. Figure 8 shows the control scheme of port 1, whose inner loop control is improved FCS-MPC with delay compensation and whose outer loop control is 


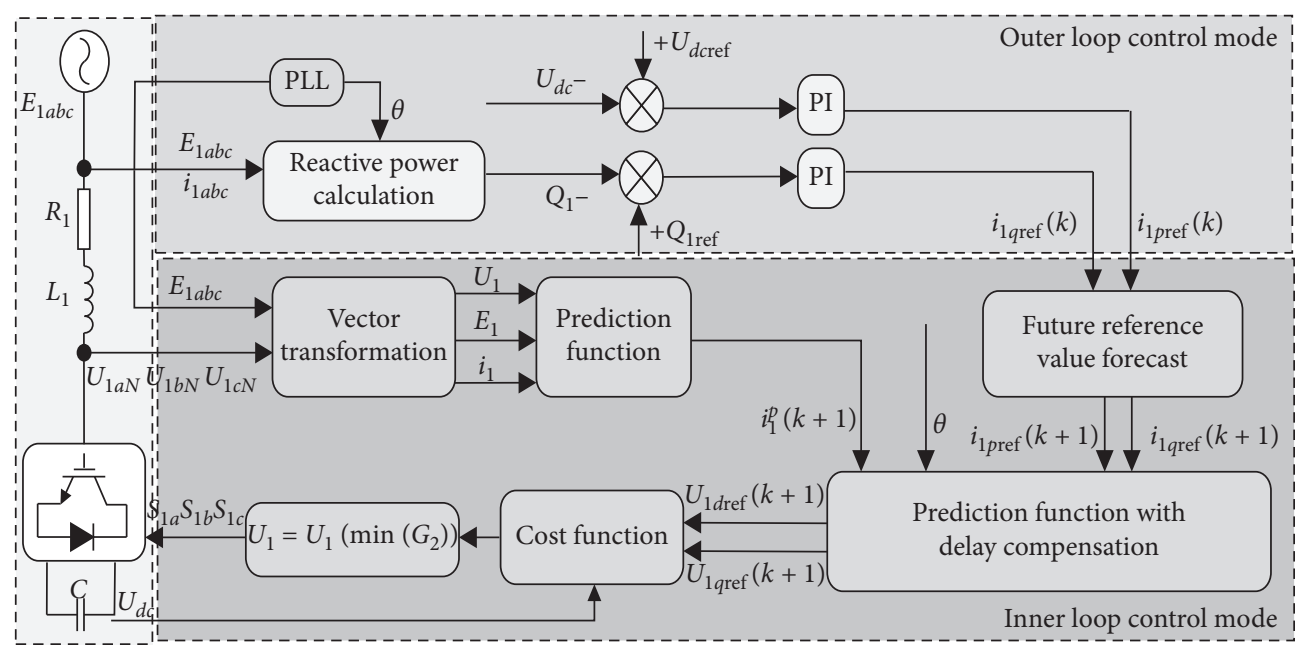

Figure 8: The control scheme of port 1.

$U_{d c} Q$ control. When the $U_{d c} Q$ control mode is adopted, the control goal of VSC1 is to control the voltage on the DC side and provide reactive power on the AC side. If self-loss is not considered, when the three-port SOP works stably, the active power of the system maintains a balanced transmission. So the $d$-axis current reference value can be obtained by inputting the error between the actual DC voltage and the reference value into the PI controller:

$$
i_{1 d \mathrm{ref}}(k)=\left(k_{p}+\frac{k_{i}}{S}\right)\left(U_{d c \mathrm{ref}}-U_{d c}\right),
$$

where $k_{p}$ and $k_{i}$ are parameters of the PI regulator and $U_{d c r e f}$ is the reference value of DC voltage. According to (12), the reactive power $Q_{1}$ can be calculated, and the error between $Q_{1}$ and the reactive power reference value $Q_{1 \text { ref }}$ can be input into the PI controller to obtain the $q$-axis current reference value $i_{\text {lqref. }}$

The reference current obtained by the outer loop control is the reference current at time $k$. In order to compensate for the delay of the reference value, the reference current at time $k$ is compensated by the vector angle compensation method (equation (25)), and the reference currents $i_{1 \text { pref }}(k+2)$ and $i_{1 q \text { ref }}(k+2)$ can be obtained. After collecting the three-phase voltage $E_{1 a b c}$ of the power grid at time $k$, the three-phase current $i_{a b c}$, and the inverter output voltages $U_{1 a N}, U_{1 b N}$, and $U_{1 c N}$, they are converted into vector forms $U_{1}(k), E_{1}(k)$, and $i_{1}(k)$ with equations (3) and (6). Then, they are input into the prediction function (equation (14)), and the predicted current value of $i_{1}^{p}(k+1)$ can be obtained.

According to (24), when the vector angle compensation method is used to compensate the power network voltage vector $E_{1}(k)$ of time $k$, the voltage vector $E_{1}(k+1)$ of time $k+1$ can be obtained. The reference voltage vector can be obtained by inputting the reference current value, current prediction value, and grid voltage prediction value into the prediction function with delay compensation (equation (17)). According to the need of the cost function, the reference voltage vector is converted to the $d q$ coordinate system to get the $d q$ axis components $U_{1 d \text { ref }}(k+1)$ and
$U_{1 \text { gref }}(k+1)$, and the output voltage vectors are converted to the $d q$ coordinate system to get the $d q$ axis components of the output voltage vectors. Then, by comparing the $d q$ axis components of the output voltage vectors and the reference voltage vector, the voltage vector that minimizes the cost function is obtained. Finally, the voltage vector is converted to the switch state and input to the VSC1 of port 1.

4.2. PQ Control Mode. Figure 9 shows the control schemes of port 2 and port 3 . Because their control schemes are similar, port 2 is taken as an example to analyze its control scheme. The inner loop control of port 2 is an improved FCS-MPC with delay compensation, but the outer loop control is $\mathrm{PQ}$ control. When using PQ control, VSC2 aims to control active power $P$ and reactive power $Q$. According to (12), the control mode of active power and reactive power can be designed. But there are some problems, such as large parameter error and slow control speed. Therefore, the PQ outer loop control in this paper adopts the steady-state inverse model. Compared with the traditional model, there is no feedback link, but it can improve the dynamic performance. By inverting (12), the formula of the steady-state inverse model can be obtained:

$$
\left\{\begin{array}{l}
i_{2 d}^{\prime}=\frac{2}{3} \frac{E_{2 d} P_{2 \mathrm{ref}}+E_{2 q} Q_{2 \mathrm{ref}}}{E_{2 d}^{2}+E_{2 q}^{2}}, \\
i_{2 q}^{\prime}=\frac{2}{3} \frac{E_{2 q} P_{2 \mathrm{ref}}-E_{2 d} Q_{2 \mathrm{ref}}}{E_{2 d}^{2}+E_{2 q}^{2}},
\end{array}\right.
$$

where $P_{2 \text { ref }}$ and $Q_{2 \text { ref }}$ are the reference values of active and reactive power, respectively, $i_{2 d}^{\prime}$ and $i_{2 q}^{\prime}$ are the reference predictions, and $E_{2 d}$ and $E_{2 q}$ are the component of the grid voltage at port 2 on the $d q$ axis.

As shown in Figure 10, the steady-state inverse model structure can be constructed according to (30). Combined with Figures 9 and 10, the outer loop control process of VSC2 is analyzed. According to (12), the actual values of 


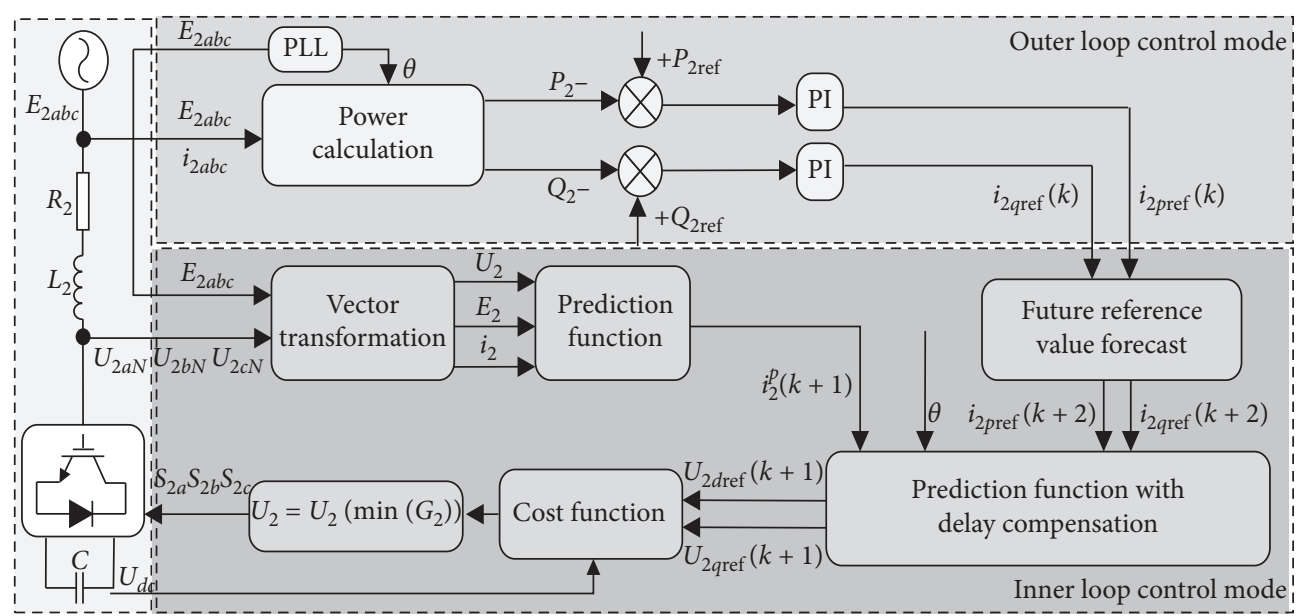

FIgure 9: The control scheme of port 2 and port 3.

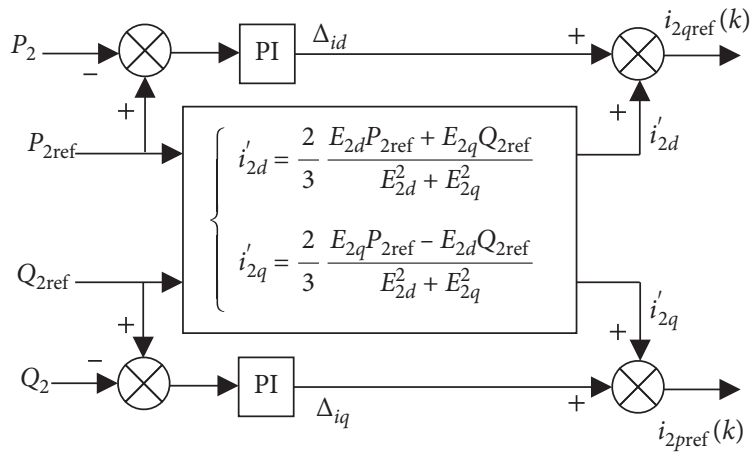

FIGURE 10: Steady-state inverse model.

power $P_{2}$ and $Q_{2}$ are calculated. Then, they are input into the steady-state inverse model. The reference predictions of the $d q$ axis components of the output current $\left(i_{2 d}^{\prime}\right.$ and $\left.i_{2 q}^{\prime}\right)$ can be obtained from (30). Through the PI controller, the differences between the actual values of active and reactive power and the corresponding reference values are converted into modified values of the corresponding current components $\left(\Delta i_{d}\right.$ and $\left.\Delta i_{q}\right)$, and then, the current reference values $\left(i_{2 \text { pref }}(k)\right.$ and $\left.i_{2 \text { qref }}(k)\right)$ are obtained by adding them. The inner loop control process is the same as above.

\section{Simulation Analysis}

In order to verify the effectiveness of the proposed control strategy, the three-port SOP simulation model shown in Figure 2 is built in MATLAB/Simulink. It is assumed that when the three-port SOP is running normally, port 1 (VSC1) runs in $U_{d c} Q$ mode, while port 2 (VSC2) and port 3 (VSC3) run in the PQ mode. The simulation parameters are shown in Table 2.

5.1. Steady-State Operation Control. The DC side reference voltage of port 1 is set to $200 \mathrm{~V}$; the reference current of port 2 is $25 \mathrm{~A}$ and that of port 3 is $20 \mathrm{~A}$. Figures 10 (a) and 11(a) show the $A$-phase current waveforms of port 2 and port 3 ,
TABLE 2: System simulation parameters.

\begin{tabular}{lc}
\hline System parameters & Numerical value \\
\hline Grid voltage amplitude, $E(\mathrm{~V})$ & 311 \\
Filter inductance, $L(\mathrm{mH})$ & 10 \\
AC side equivalent resistance, $R(\Omega)$ & 0.3 \\
DC side capacitor, $C(\mu f)$ & 800 \\
DC side voltage, $U_{d c}(\mathrm{~V})$ & 200 \\
Sampling interval, $t(\mu s)$ & 10 \\
\hline
\end{tabular}

respectively. It can be seen from the figure that the actual current can accurately track the reference current and there is no steady-state error. Figures $11(\mathrm{~b})$ and 12 (b) show the three-phase output current of port 2 and port 3 , respectively. It can be seen that although the reference current of the two ports is different, the quality of their output current is still very high. Figures 11(c) and 12(c) show the output power of port 2 and port 3 , respectively. It can be seen from the figure that the steady-state power output is also very stable and the waveform is smooth and does not fluctuate. Figure 13 shows the DC side voltage waveform; it can be seen that the DC voltage only needs less than $0.01 \mathrm{~s}$ to track the reference value, and the voltage can be kept stable without fluctuation after reaching the steady state. Figure 14 shows the power transmission diagram of the three ports; it can be seen that the stability of the DC side voltage can ensure the stable power transmission. The output power of one port is equal to the output power of the other two ports.

5.2. Dynamic Operation Control. Assuming that, at $0.25 \mathrm{~s}$, there is a $5 \mathrm{~A}$ fluctuation in the reference current of port 3 . The change of the waveform is shown in Figure 15. To facilitate the analysis, the output current is converted to the $d q$ coordinate system, as shown in Figures 13 and 14. As can be seen from Figure 15(a), the current can respond quickly and reach a steady state again when it encounters a step change, and the whole step process takes less than $0.4 \mathrm{~ms}$. At the same time, Figure 15(b) shows the change of power corresponding to the change of the current on the $d q$ axis. The $d$-axis current component changes from $20 \mathrm{~A}$ to $25 \mathrm{~A}$, and 


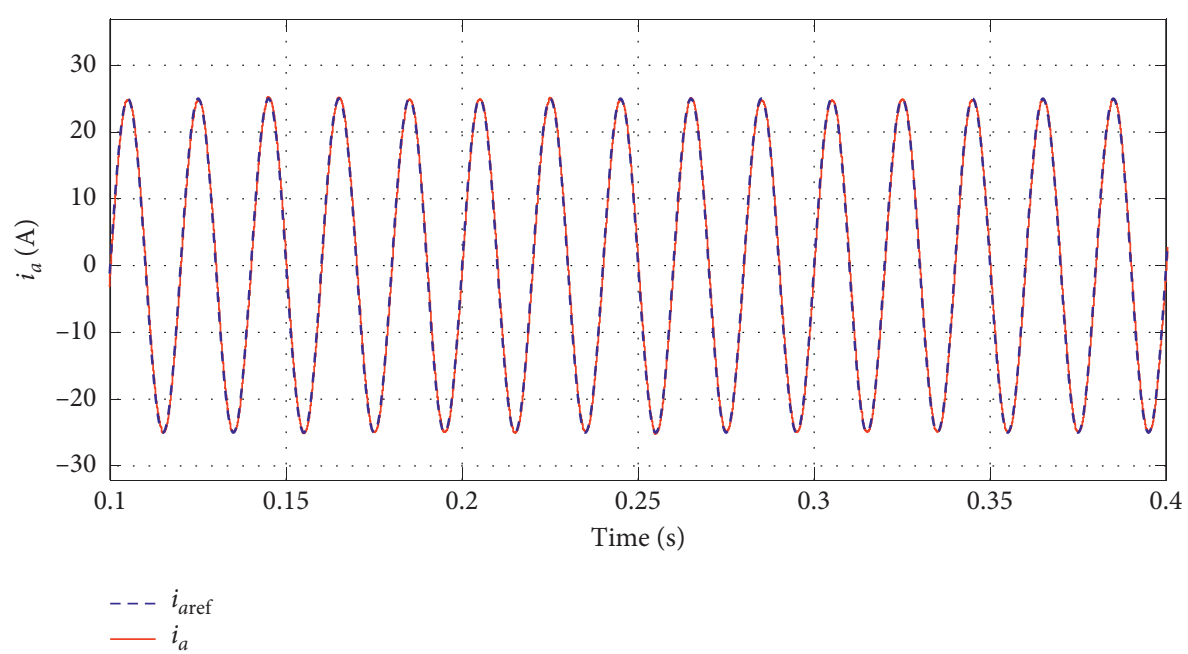

(a)

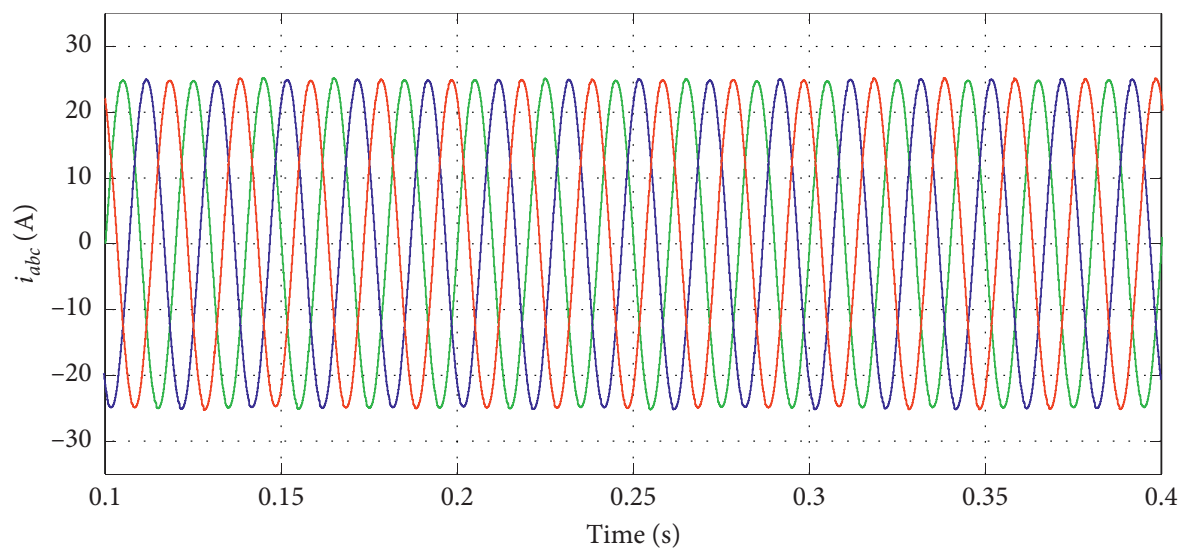

$i_{a}$
$-i_{b}$
$-i_{c}$

(b)

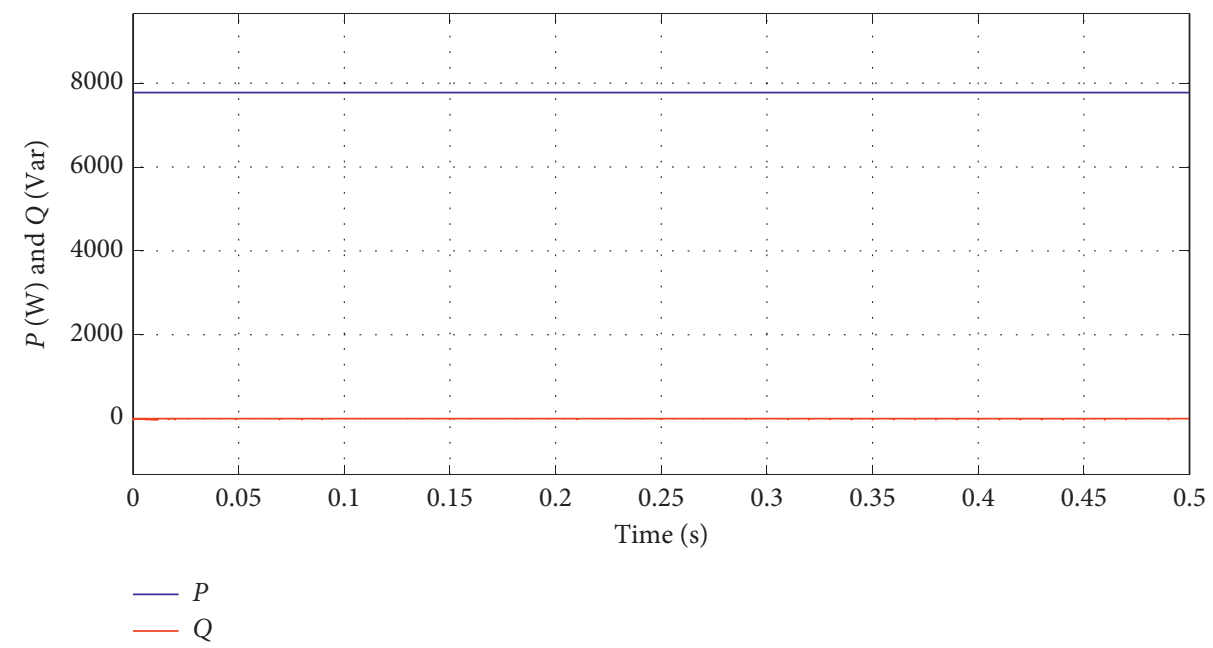

(c)

Figure 11: Response waveform of port 2 under improved FCS-MPC. (a) A-phase current waveform. (b) Port output current waveform. (c) Port output power. 


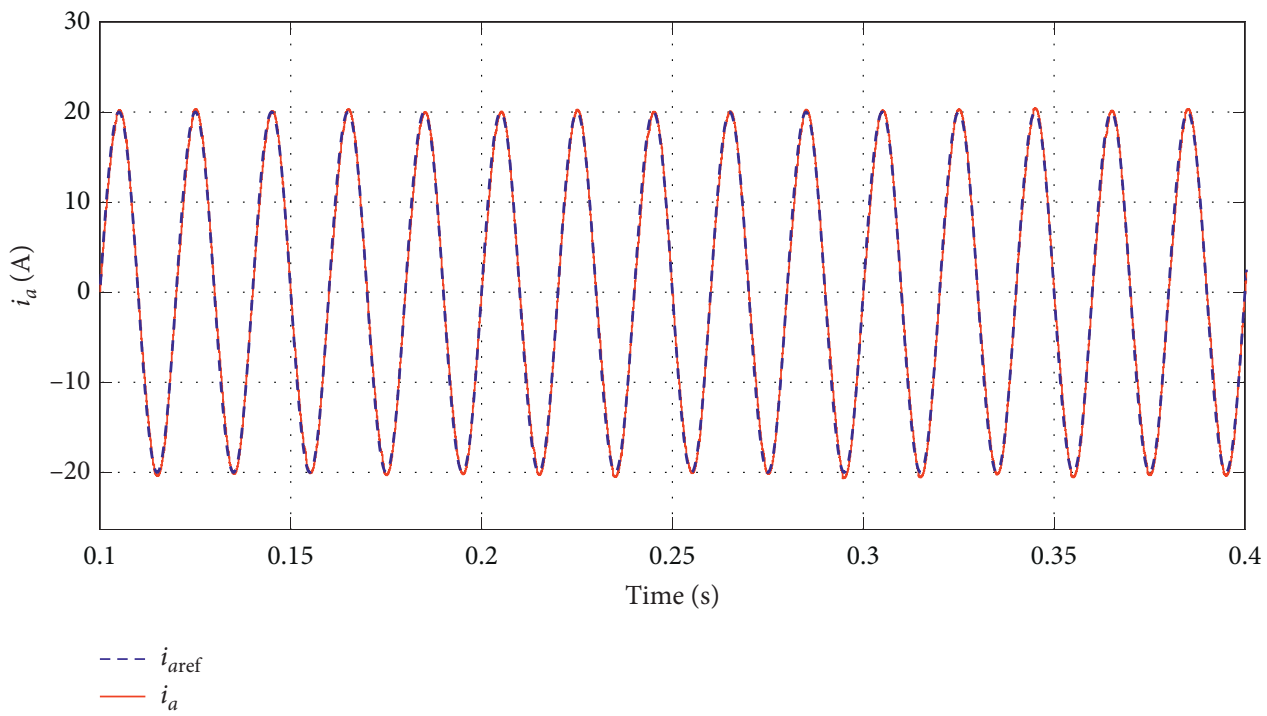

(a)

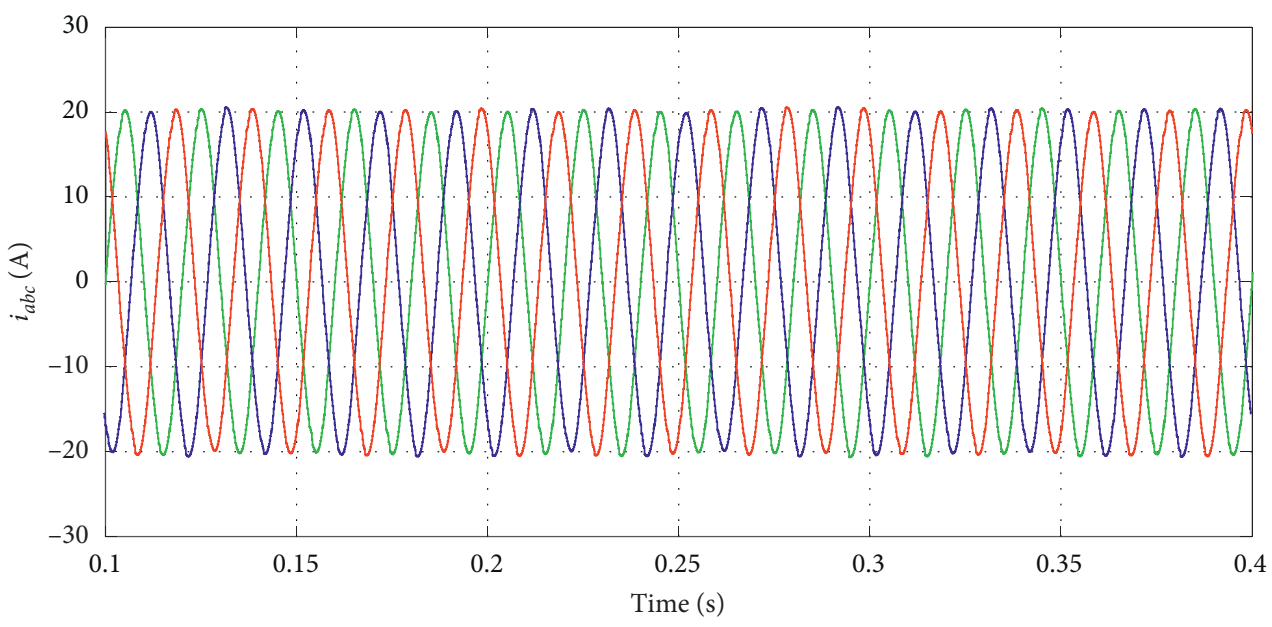

$-i_{a}$
$-i_{b}$
-

(b)

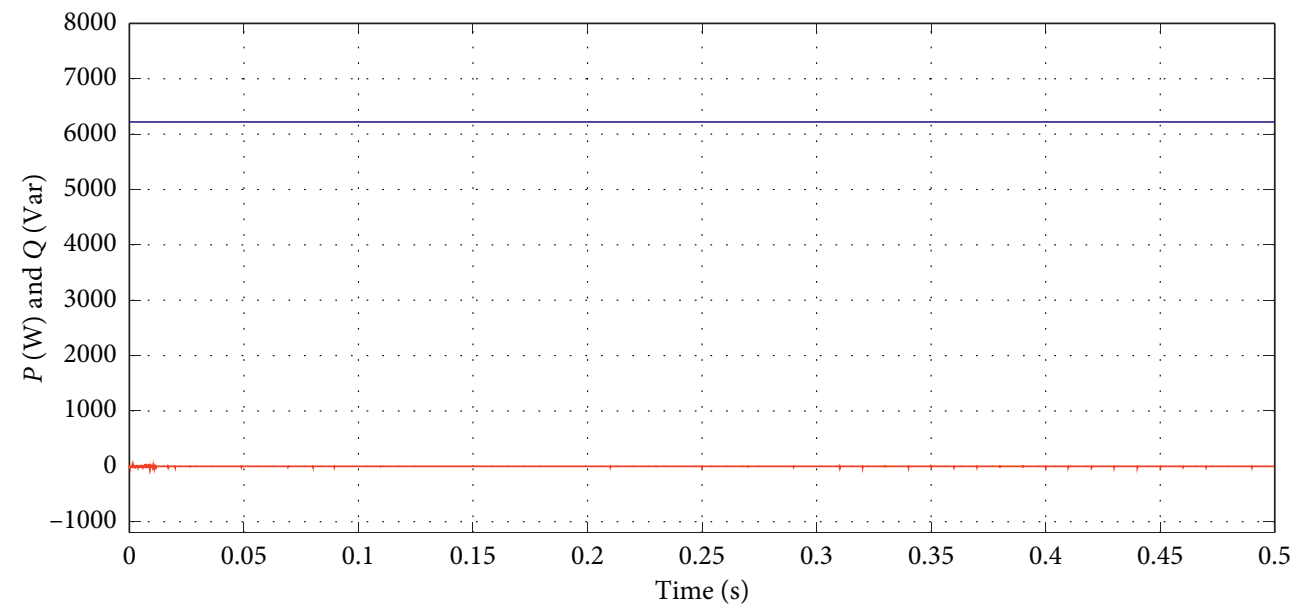

$-P$

(c)

FIgURE 12: Response waveform of port 3 under improved FCS-MPC. (a) A-phase current waveform. (b) Port output current waveform. (c) Port output power. 


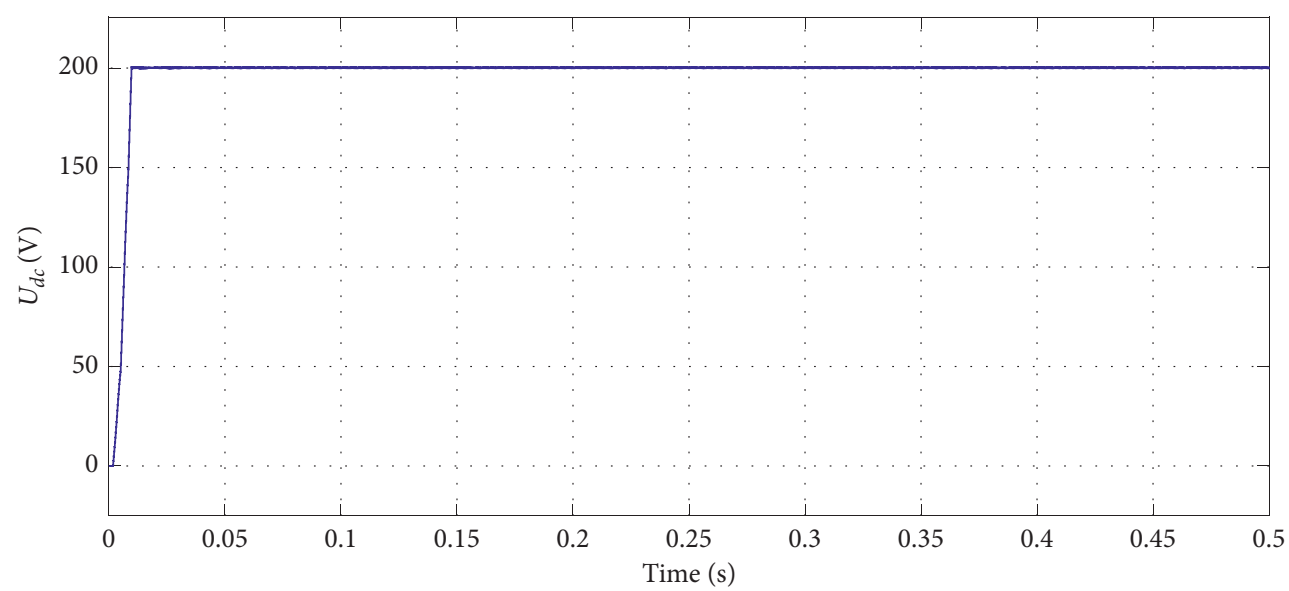

Figure 13: DC side voltage waveform.

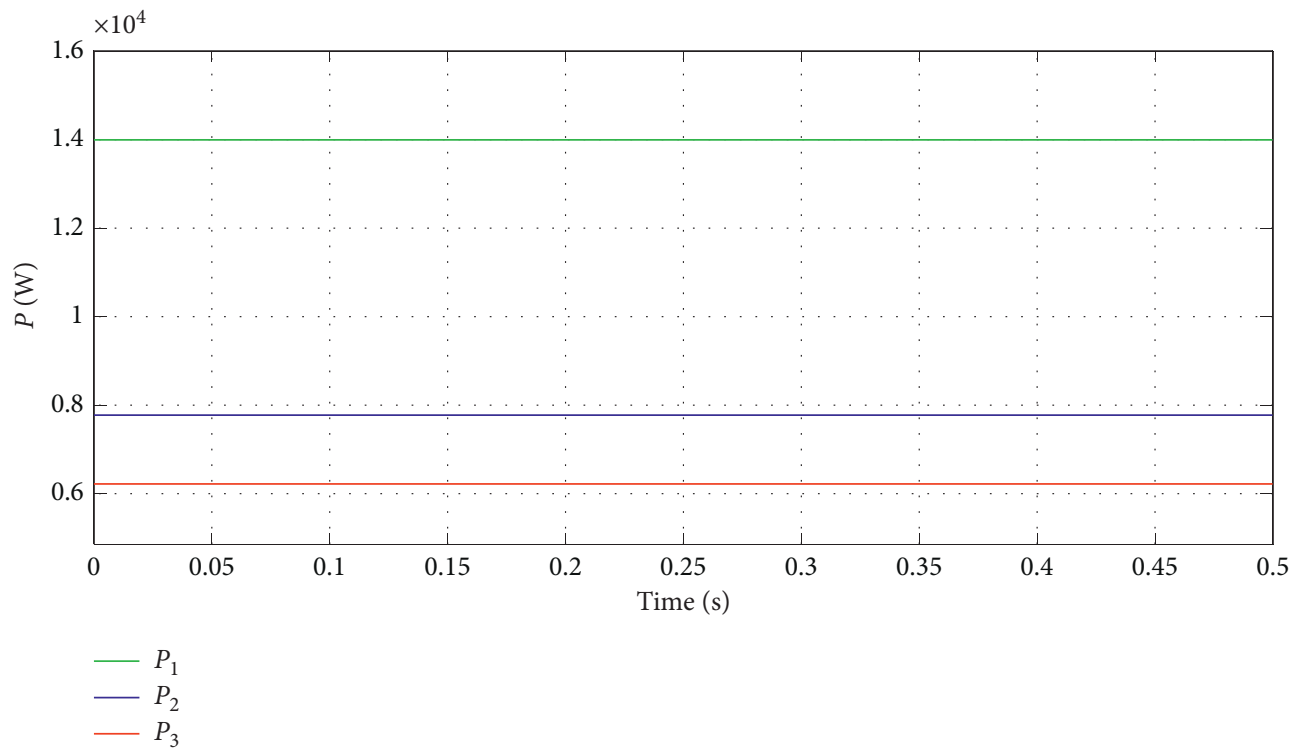

FIGURE 14: Active power response waveform of three ports.

the active power changes from $6.2 \mathrm{~kW}$ to $7.7 \mathrm{~kW}$. The $q$-axis current component and the reactive power remain equal to zero, which is not affected by the current step. It shows that both current components of $d q$ axis and power can be decoupled. Figure 15(c) shows a three-phase output current, which indicates that the high-quality power output can be maintained after the current change.

Figures 16(a)-16(c) show the change of the current component on the $d q$ axis, power, and three-phase current of port 2, respectively. It can be seen that the control of port 2 can keep the output current and power stable. Figure 17 shows the DC side voltage waveform. It can be seen from the figure that the DC voltage does not change, which indicates that the control of port 1 can keep the DC side voltage stable. The current fluctuation of port 3 does not affect the control effect of other ports, which shows that the three ports can be controlled independently and realize the function of fault isolation. Figure 18 shows the power transmission waveform among the three ports. It can be seen from the figure that the power change of port 3 will cause the power change of port 1 , which indicates that the power transmission between ports is in dynamic balance and the transmission is stable.

\subsection{Comparison and Analysis}

5.3.1. Comparative Analysis with Double Closed-Loop Control. In the actual operation process, the system often needs to adjust the size of the reference value according to the needs. The response speed of the two control schemes is compared by setting the reference current from $20 \mathrm{~A}$ to $25 \mathrm{~A}$. Figures 19(a) and 19(b) show the change of the current component of the $d q$ axis under the double closed-loop control and the improved FCS-MPC, respectively. It can be seen from the figure that the current under the double closed-loop control needs to go through the step process of 


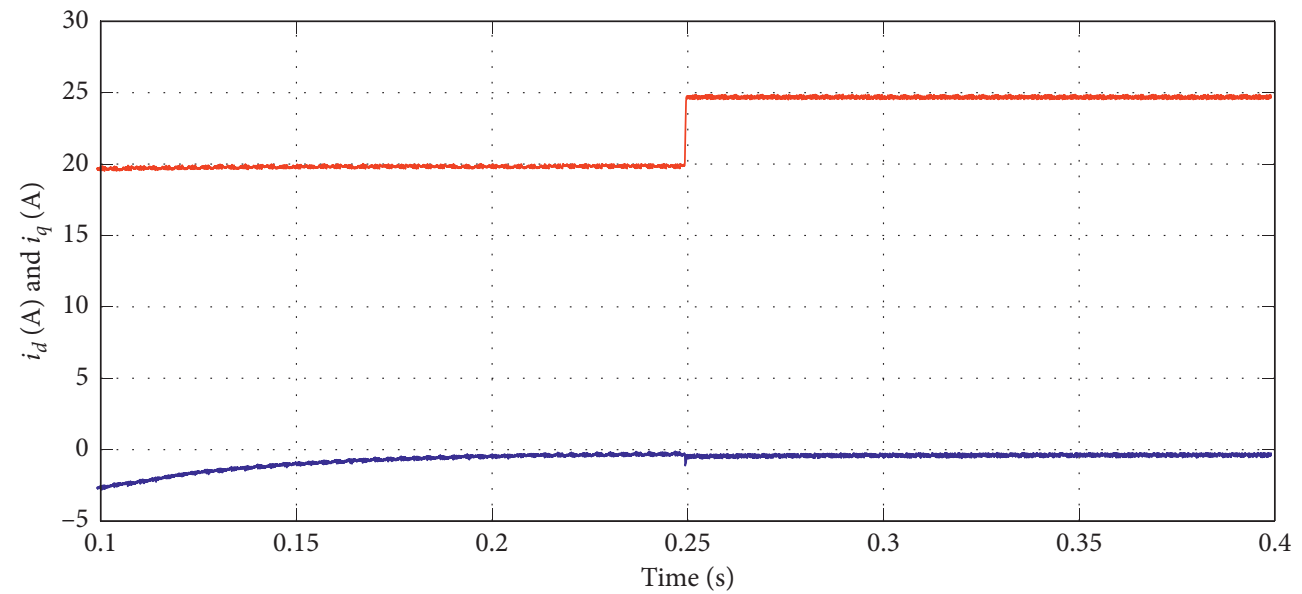

$-i_{d}$

$-i_{q}$

(a)

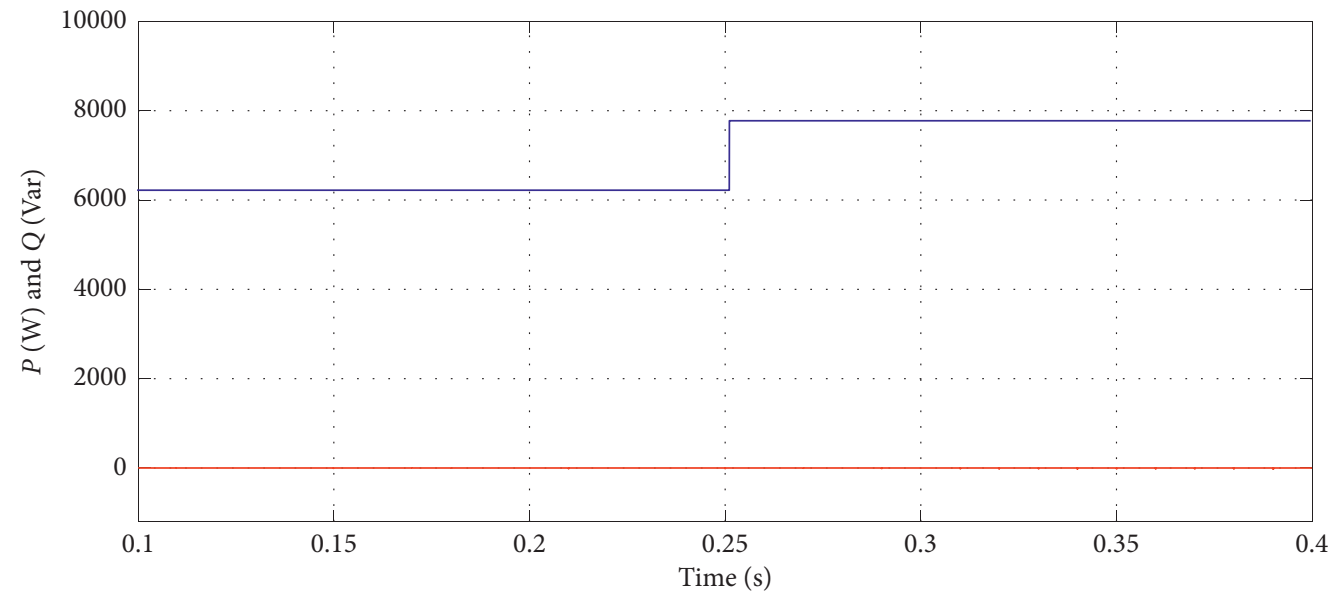

$P$
-

(b)

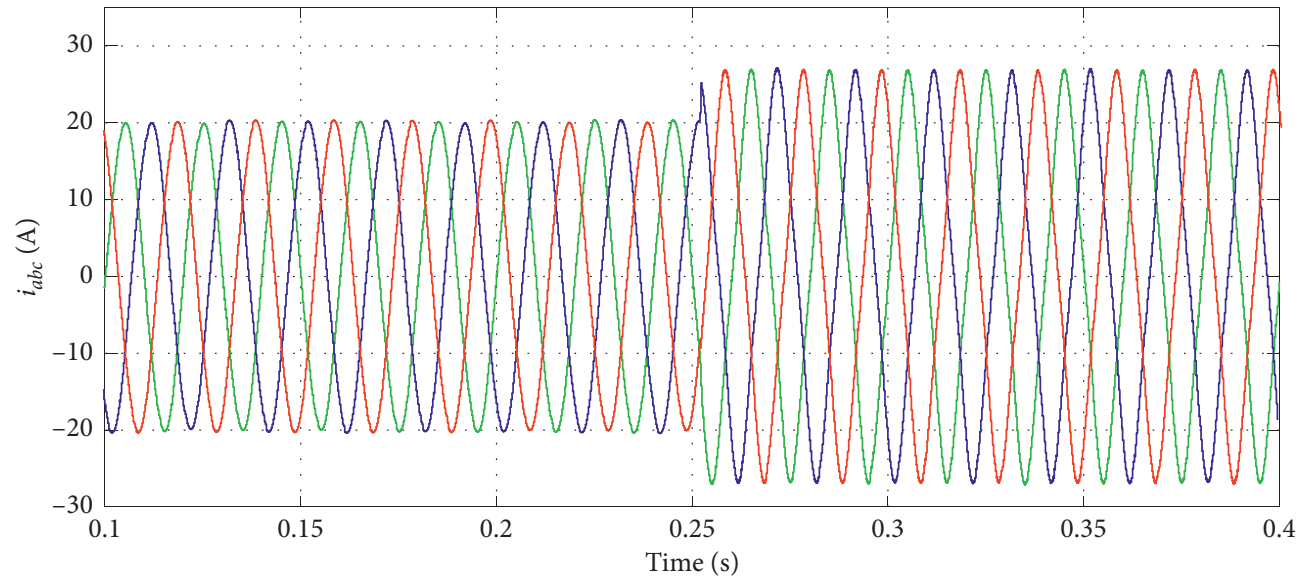

$-i_{a}$
$-i_{b}$
$-i_{c}$

(c)

FigURE 15: Waveform change of port 3 when reference current fluctuates. (a) Load current component on the $d q$ axis. (b) Diagram of power change. (c) Three-phase current variation diagram. 


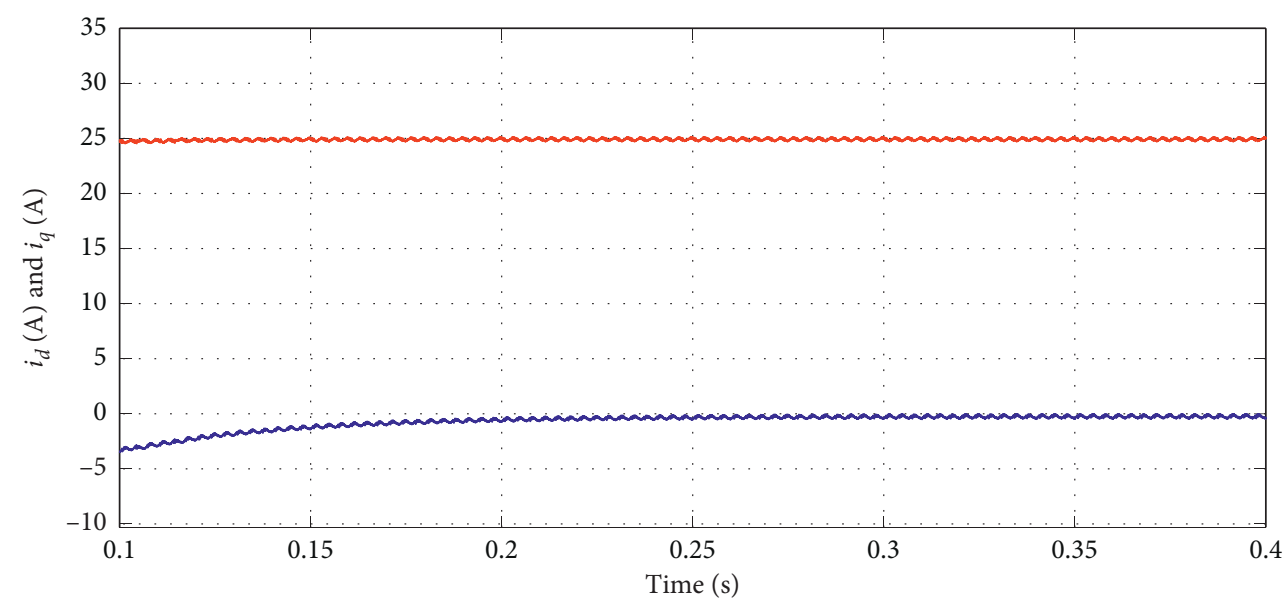

$i_{d}$

(a)

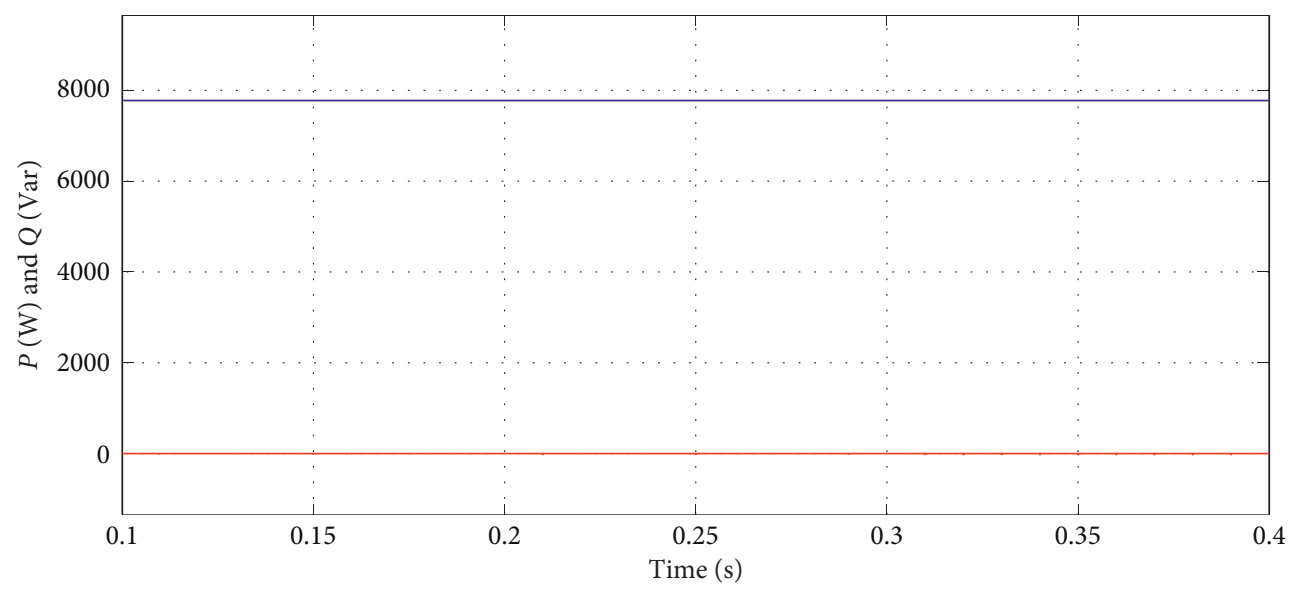

$-P$

(b)

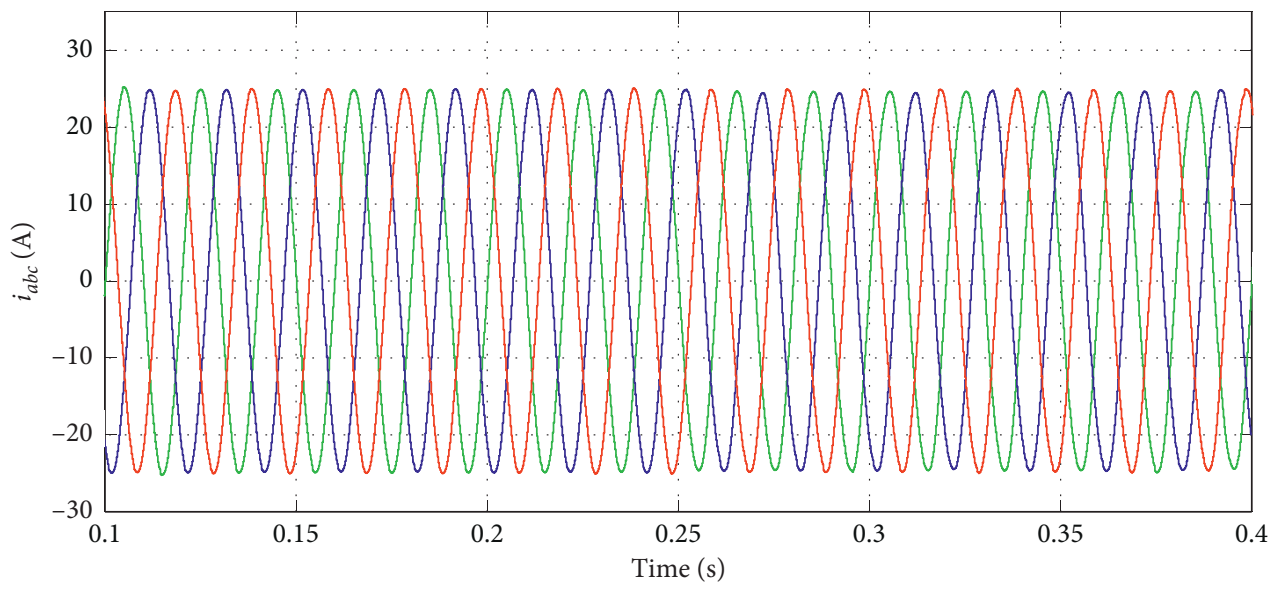

$-i_{a}$
$-i_{b}$
$-i_{c}$

(c)

FIGURE 16: Waveform change of port 2 when reference current fluctuates. (a) Load current component on the $d q$ axis. (b) Diagram of power change. (c) Three-phase current variation diagram. 


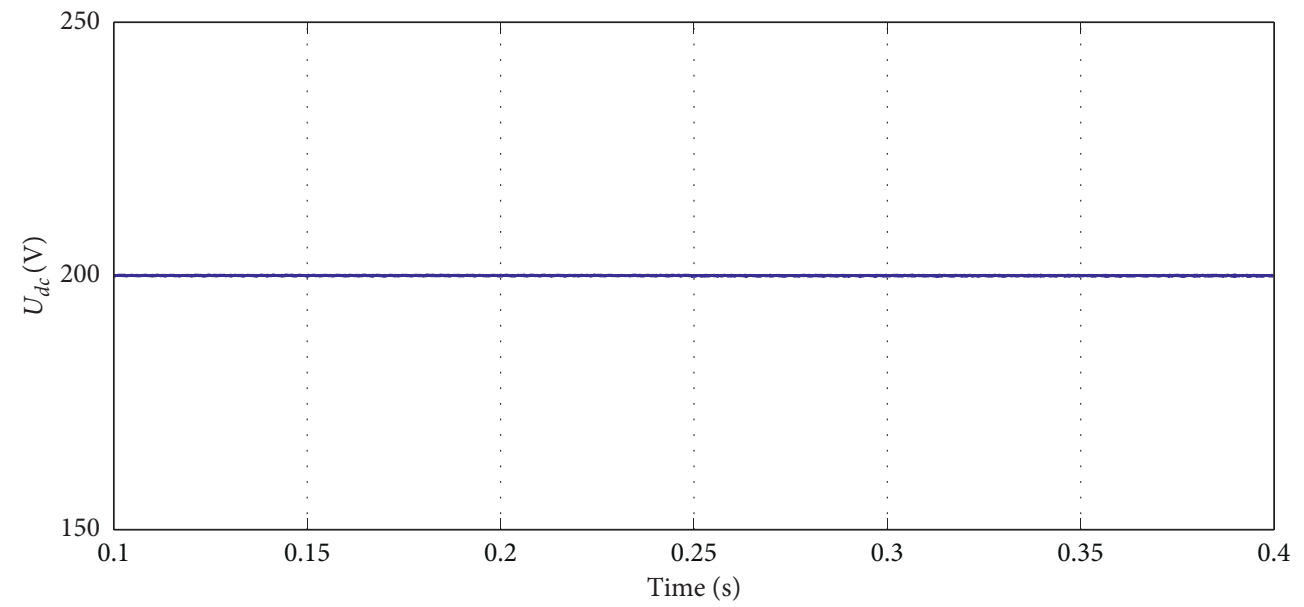

FIGURE 17: DC side voltage change. Change of transmission power of three ports when reference current fluctuates.

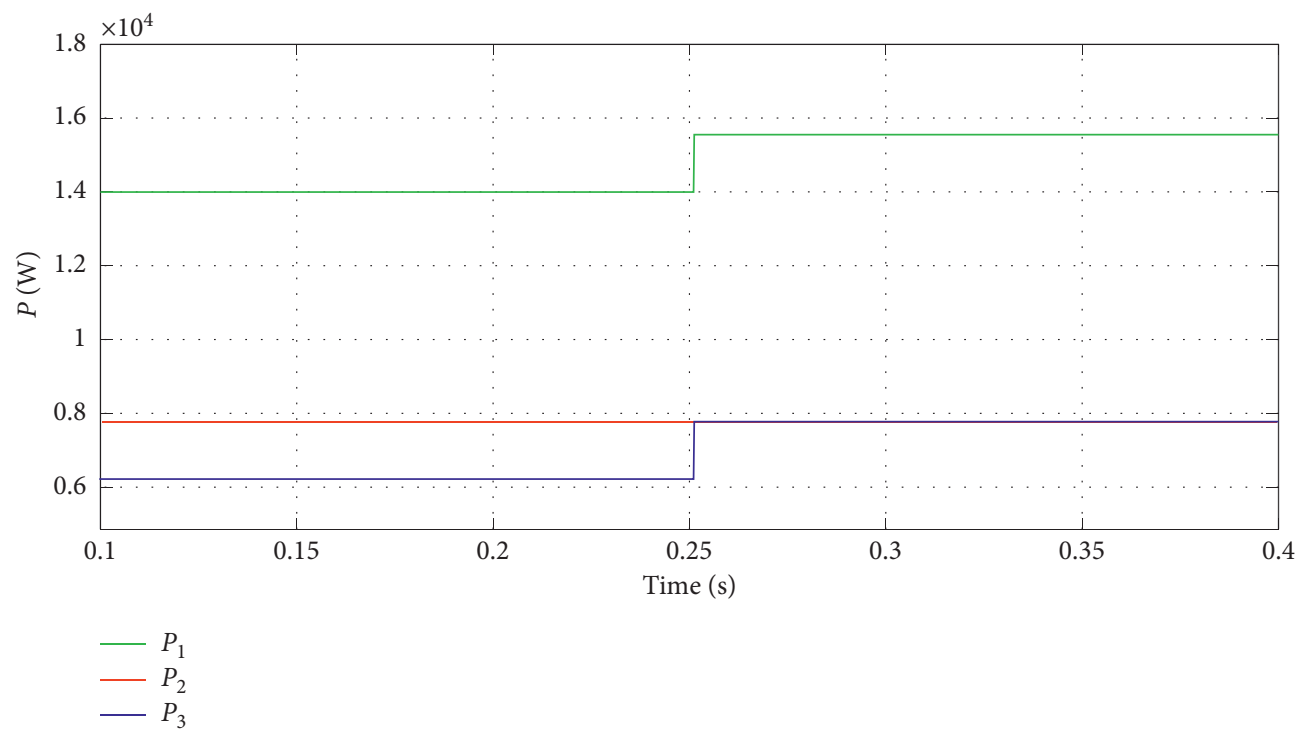

Figure 18: Change of transmission power of three ports when reference current fluctuates.

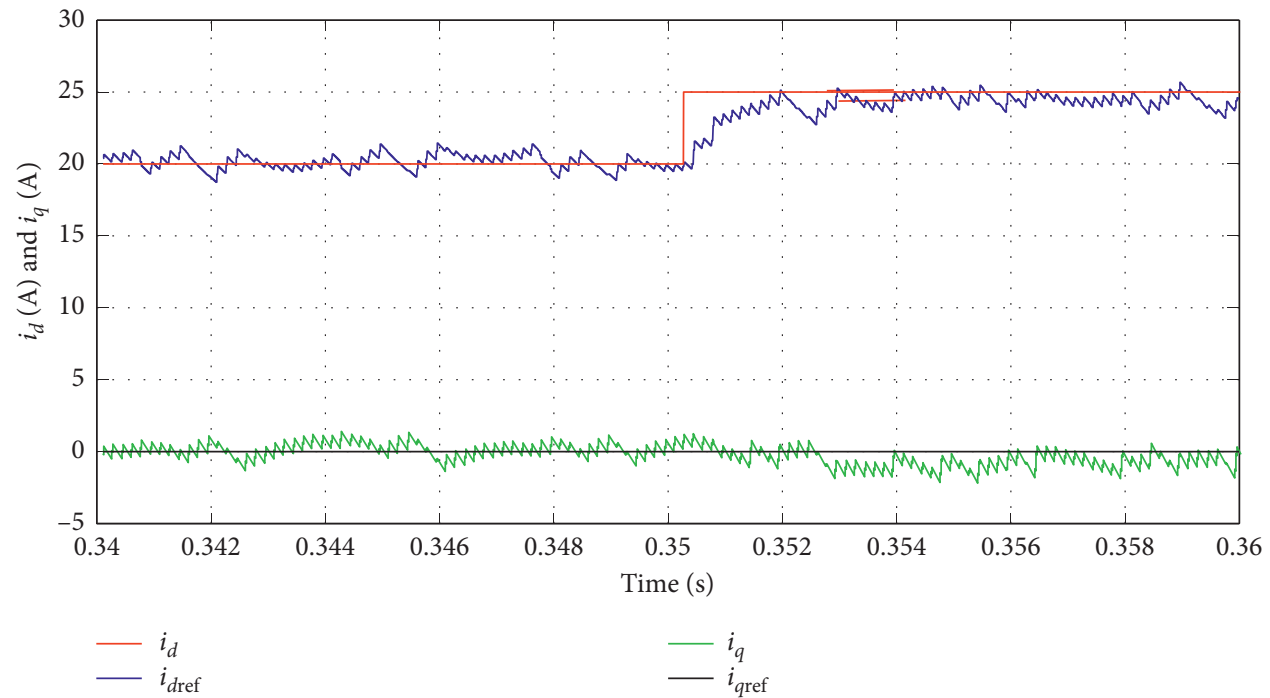

(a)

Figure 19: Continued. 


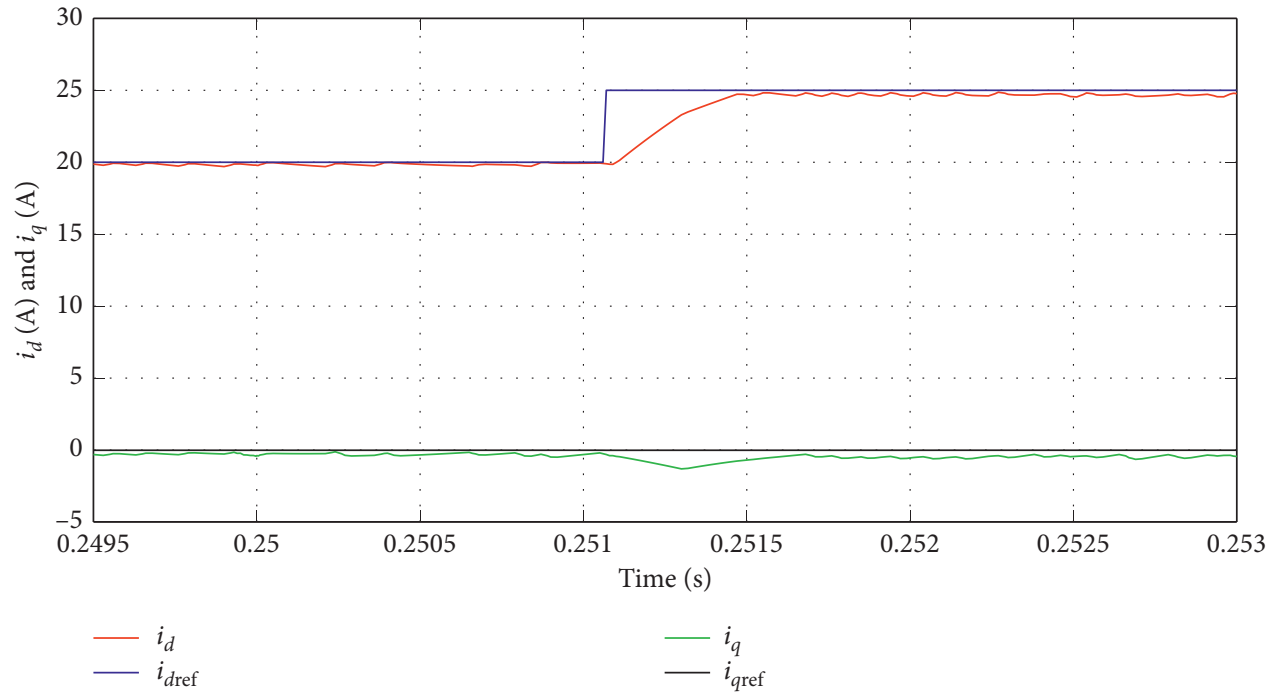

(b)

FIGURE 19: Comparison of current components of the $d q$ axis under two control schemes in terms of current changes. (a) Double closedloop control. (b) Improved FCS-MPC.

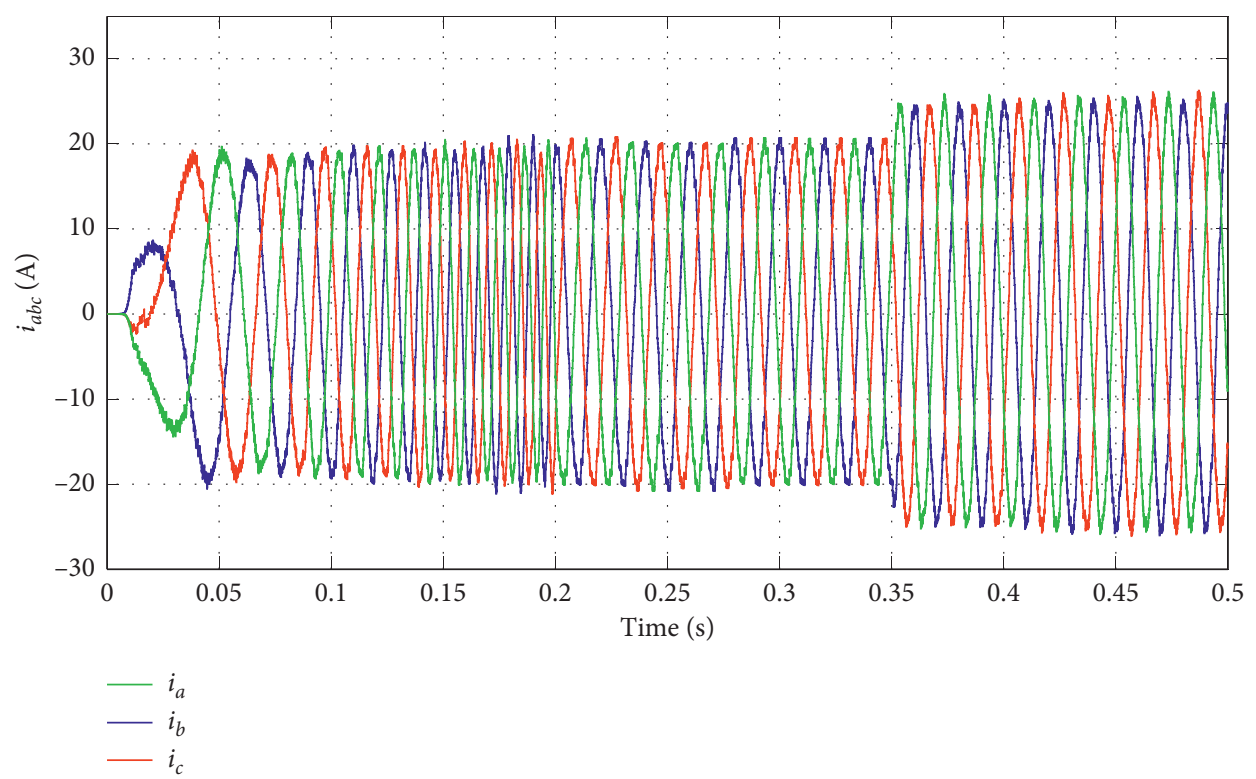

(a)

Figure 20: Continued. 


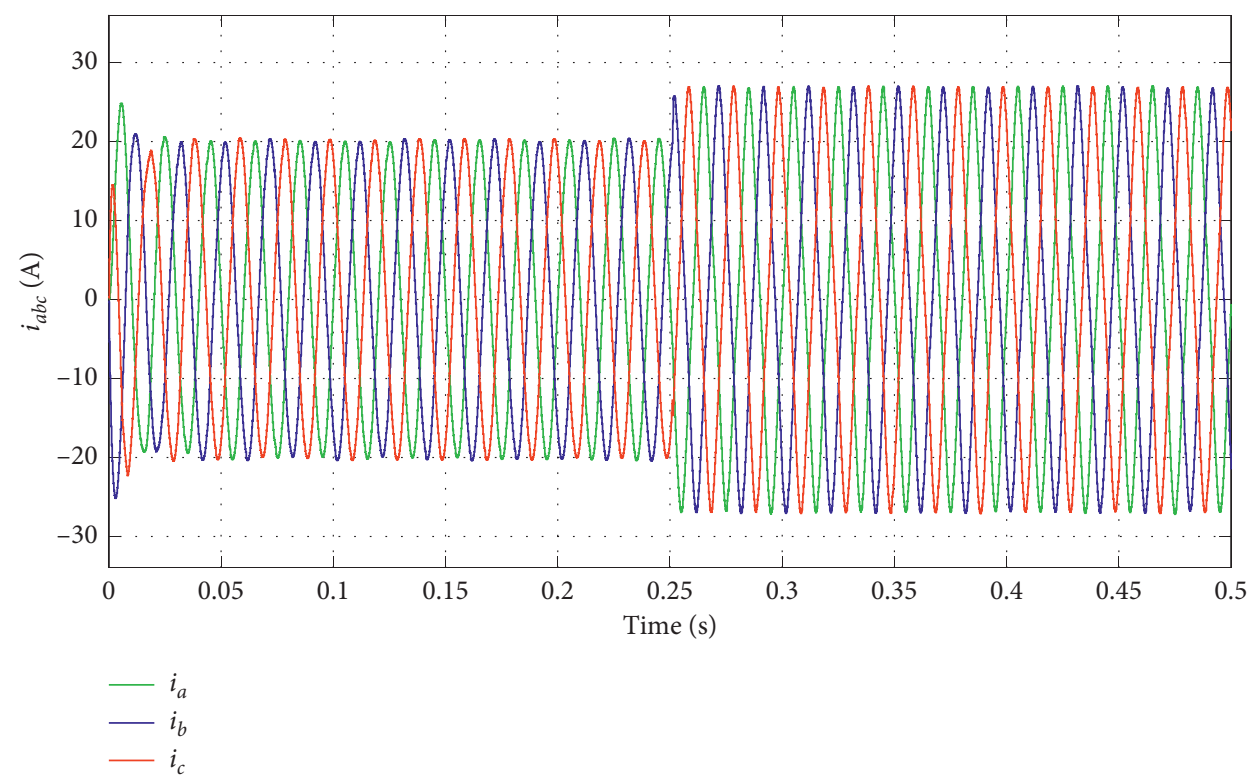

(b)

Figure 20: Comparison of three-phase current under two control schemes in terms of current changes. (a) Double closed-loop control. (b) Improved FCS-MPC.

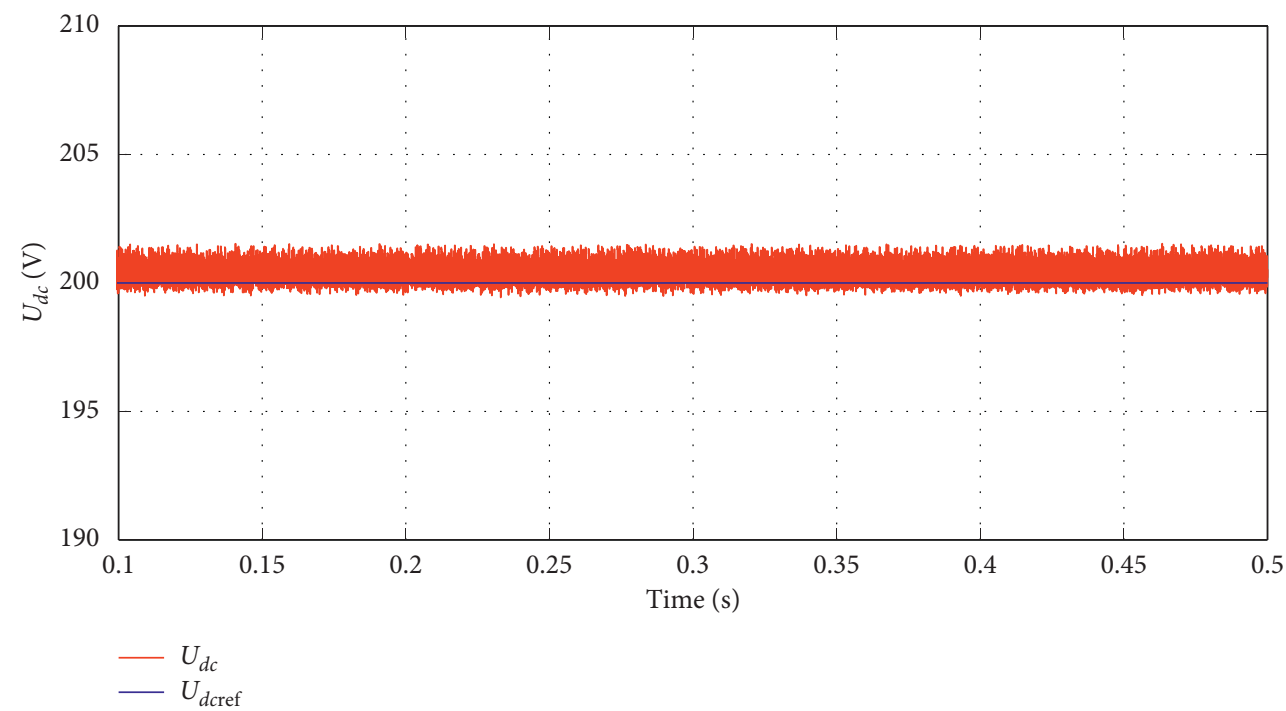

(a)

Figure 21: Continued. 


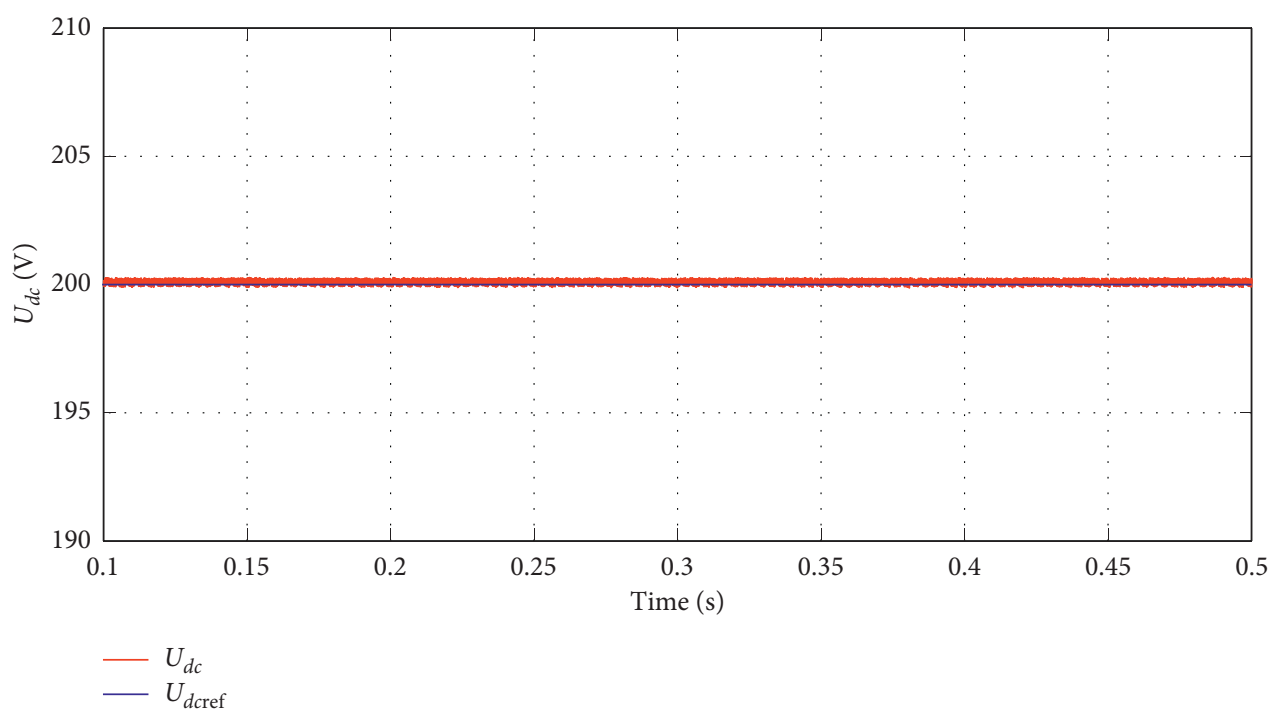

(b)

FIgURE 21: Comparison of DC side voltage under two control schemes in the steady state. (a) FCS-MPC. (b) Improved FCS-MPC.

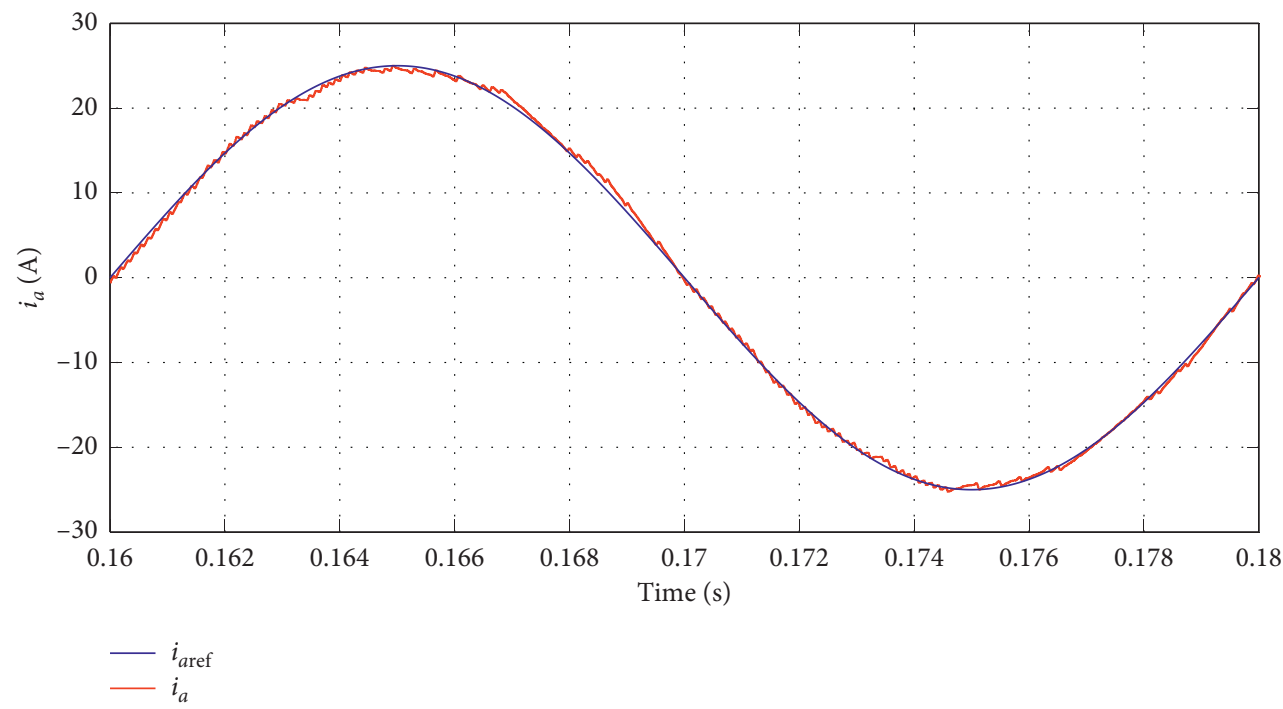

(a)

Figure 22: Continued. 


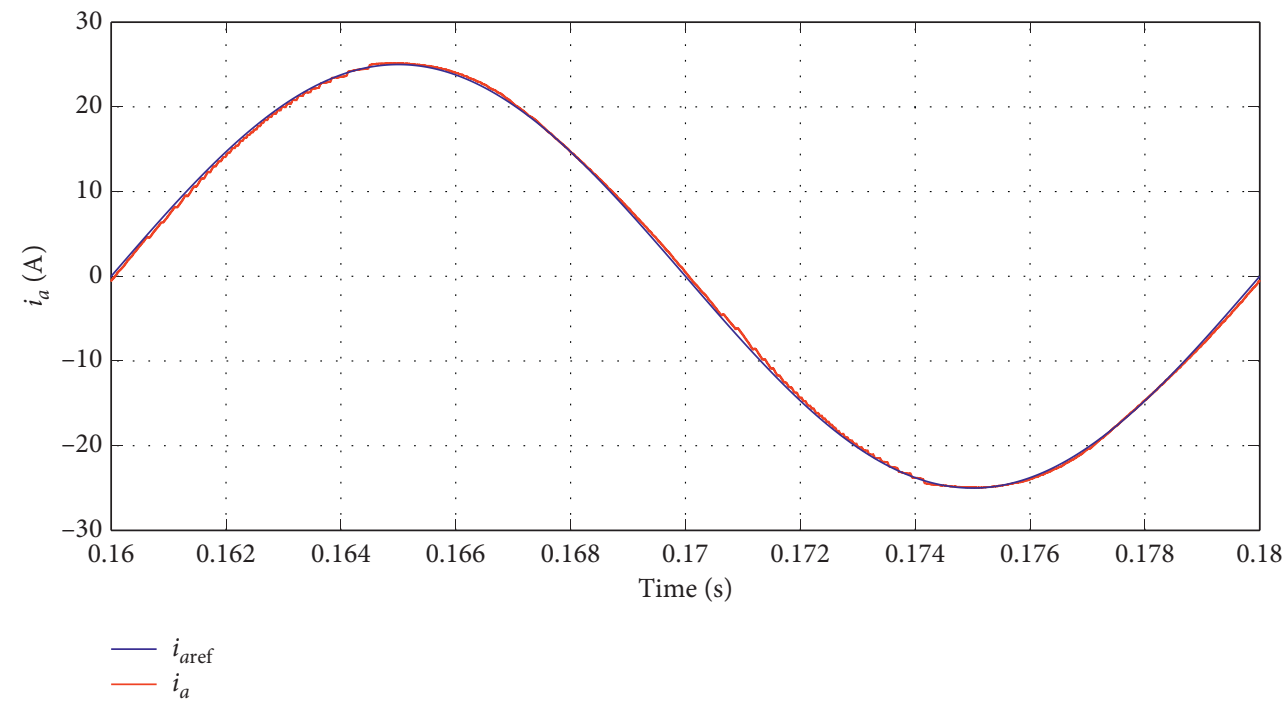

(b)

Figure 22: Comparison of $A$-phase current under two control schemes in the steady state. (a) FCS-MPC. (b) Improved FCS-MPC.

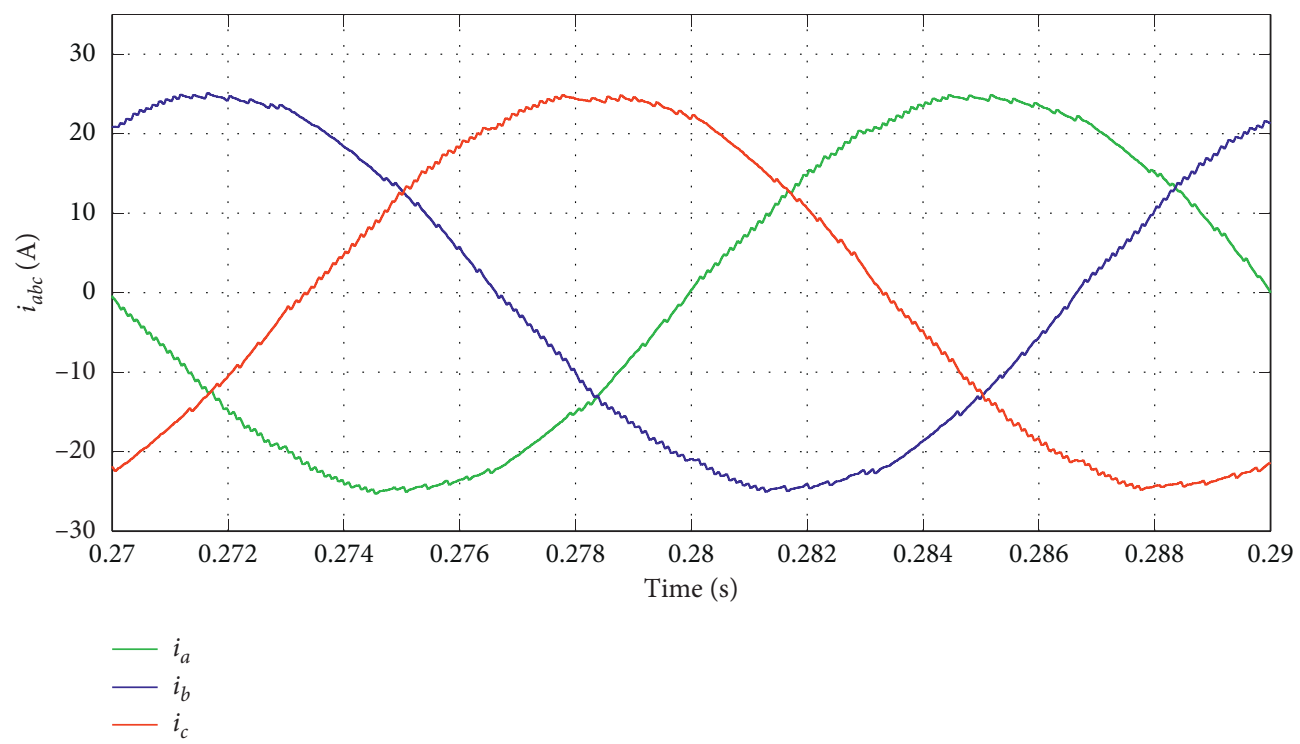

(a)

Figure 23: Continued. 


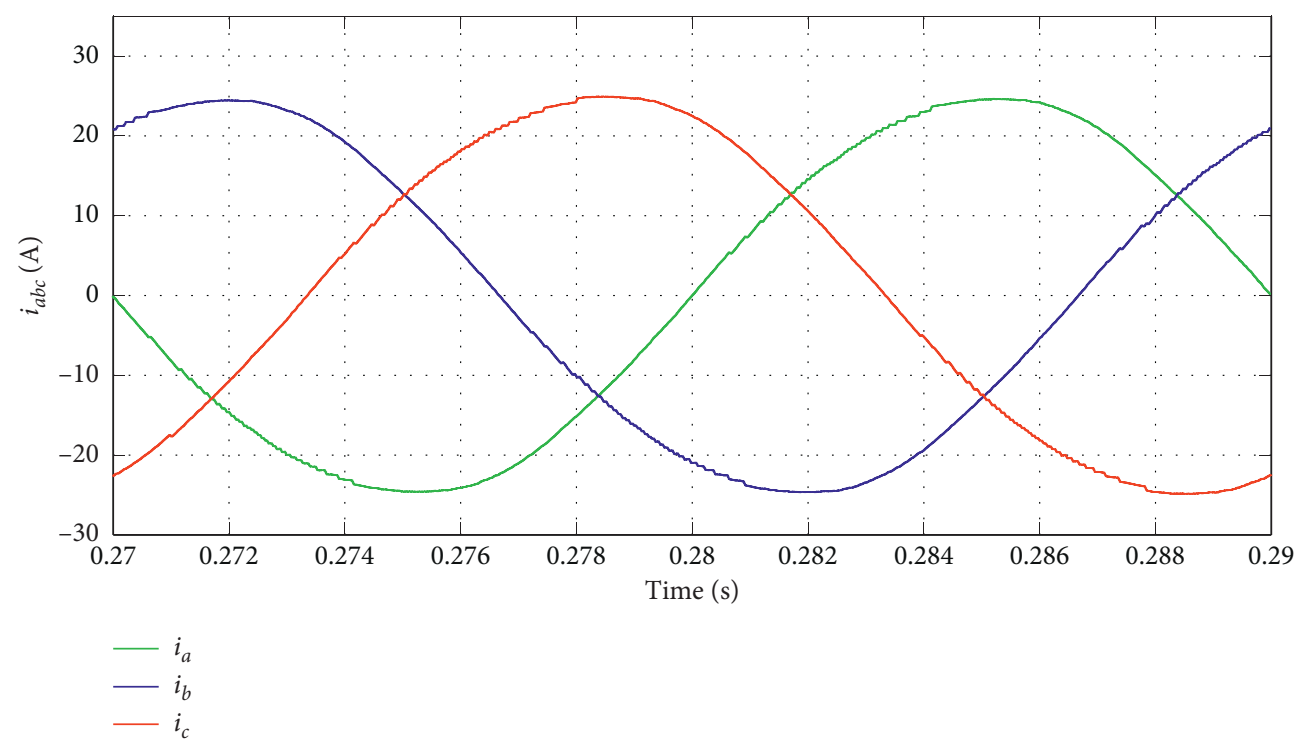

(b)

FIgURE 23: Comparison of three-phase currents under two control schemes in the steady state. (a) FCS-MPC. (b) Improved FCS-MPC.

$1.8 \mathrm{~ms}$ to reach the steady state again, whereas the current of the improved FCS-MPC only needs $0.4 \mathrm{~ms}$ to reach the steady state again. It can be seen from Figures 20(a) and 20 (b) that regardless of the initial time or step time, the steady-state output current of the improved FCS-MPC is faster than that of the double closed-loop control, which shows that the improved FCS-MPC control scheme has the characteristic of rapid response. Not only that, but the output current ripple of the improved FCS-MPC is also lesser, which is beneficial to the improvement of power quality.

5.3.2. Comparative Analysis with FCS-MPC. FCS-MPC itself also has a faster response speed, but due to its large amount of calculation, it will cause current delay and other problems, which will reduce the accuracy of the actual current tracking reference current. The reference current is set to $20 \mathrm{~A}$, and the DC side reference voltage is set to $200 \mathrm{~V}$ to compare the steady-state current and voltage tracking accuracy of FCS-MPC and improved FCS-MPC. Figure 19 displays a comparison of the DC side voltage tracking effect. Comparing Figures 21(a) and 21(b), it can be seen that, at the same sampling frequency, the DC side voltage of the improved FCS-MPC is closer to the reference voltage and the tracking effect is better. The DC side voltage of FCS-MPC has more ripples. Excessive ripples will increase the loss of the power grid and reduce transmission efficiency. Figure 20 displays a comparison of the current tracking effect of $A$ phase. The current delay will cause a large deviation when the actual current tracks the reference current. Comparing Figures 22(a) and 22(b), it can be seen that due to the obvious deviation between the reference current and the actual current, the current of FSC-MPC has a relatively serious delay problem, but due to the small deviation between the reference current and the actual current, the improved FCS-MPC can solve the current delay problem and improve the current tracking accuracy. Figure 23 displays a three-phase output current comparison. Comparing Figures 23(a) and 23(b), it can be seen that the three-phase output current waveform of the improved FCS-MPC is smoother, which can effectively improve the power quality of the distribution network.

\section{Conclusion}

To realize the decoupling control between the variables of the system, this paper uses the vector method and $d q$ coordinate transformation method to establish a three-port SOP mathematical model. The control scheme designed in this paper combines the advantages of FCS-MPC while improving its shortcomings. In view of a large amount of calculation and the delay problem of FCS-MPC, the two-step prediction method based on the voltage vector and the vector angle compensation method is used in combination to compensate for the current delay problem in this paper. The control target is converted from the grid-connected current to the output voltage vector of each port of SOP to reduce the amount of calculation, and then, an improved FCS-MPC is proposed. Using the improved FCS-MPC instead of the inner loop current control of the double closedloop control can reduce PI parameters and reduce the difficulty of the control system design. The simulation results show that the proposed control scheme improves the accuracy of the current tracking reference value while ensuring fast dynamic response speed, effectively reduces the current and voltage ripple, improves the output power quality, and improves the power distribution network, which provide new ideas for improving the flexibility and stability of the distribution network.

When the system is subjected to external interference, changes in the operating environment, saturation of the 
magnetic circuit of electromagnetic components, system overload, etc., the parameters of the resistance, inductance, capacitance, and other components in the SOP will change. The change of the parameter will also affect the predicted value and lead to a decrease in control performance. Therefore, the next step of the research will consider using discrete parameter observers to estimate the inductance and capacitance values of the system in real time. Since the change of parameters can be regarded as a kind of disturbance, the system model can be compensated in real time by establishing a disturbance observer to observe the change of disturbance.

\section{Data Availability}

The data used to support the findings of this study are included within the article.

\section{Conflicts of Interest}

The authors declare that there are no conflicts of interest regarding the publication of this paper.

\section{Acknowledgments}

The authors thank LetPub (https://www.letpub.com) for its linguistic assistance and scientific consultation during the preparation of this manuscript. This study was supported by the Natural Science Research Project of Jiangsu Higher Education Institution (18KJD470004), Strategic Priority Research Program of Chinese Academy of Sciences (XDA21050304), Open Research Fund of Jiangsu Collaborative Innovation Center for Smart Distribution Networks (XTCX201809), Fundamental Research Special Project of NJIT (JCYJ201816), University Student Science and Technology Innovation Fund Project of NJIT (TB20211638 and TB20211644), and Postgraduate Research \& Practice Innovation Program of Jiangsu Province (SJCX21_0946).

\section{References}

[1] R. Wang, Q. Sun, D. Ma, and Z. Liu, "The small-signal stability analysis of the droop-controlled converter in electromagnetic timescale," IEEE Transactions on Sustainable Energy, vol. 10, no. 3, pp. 1459-1469, 2019.

[2] Q. Sun, R. Han, H. Zhang, J. Zhou, and J. M. Guerrero, “A multiagent-based consensus algorithm for distributed coordinated control of distributed generators in the energy internet," IEEE Transactions on Smart Grid, vol. 6, no. 6, pp. 3006-3019, 2015.

[3] I. Konstantelos, S. Giannelos, and G. Strbac, "Strategic valuation of smart grid technology options in distribution networks," IEEE Transactions on Power Systems, vol. 32, no. 2, pp. 1293-1303, 2017.

[4] C. Long, J. Wu, L. Thomas, and N. Jenkins, "Optimal operation of soft open points in medium voltage electrical distribution networks with a distributed generation," Applied Energy, vol. 184, pp. 427-437, 2016.

[5] W. Cao, J. Wu, N. Jenkins, C. Wang, and T. Green, "Operating principle of soft open points for electrical distribution network operation," Applied Energy, vol. 164, pp. 245-257, 2016.
[6] W. Cao, J. Wu, N. Jenkins, C. Wang, and T. Green, "Benefits analysis of soft open points for electrical distribution network operation," Applied Energy, vol. 165, pp. 36-47, 2016.

[7] P. Li, H. Ji, C. Wang et al., "Coordinated control method of voltage and reactive power for active distribution networks based on soft open point," IEEE Transactions on Sustainable Energy, vol. 8, no. 4, pp. 1430-1442, 2017.

[8] J. Wang, N. Zhou, C. Y. Chung, and Q. Wang, "Coordinated planning of converter-based DG units and soft open points incorporating active management in unbalanced distribution networks," IEEE Transactions on Sustainable Energy, vol. 11, no. 3, pp. 2015-2027, 2020.

[9] P. Li, H. Ji, C. Wang et al., "Optimal operation of soft open points in active distribution networks under three-phase unbalanced conditions," IEEE Transactions on Smart Grid, vol. 10, no. 1, pp. 380-391, 2019.

[10] F. Sun, J. Ma, M. Yu, and W. Wei, "Optimized two-time scale robust dispatching method for the multi-terminal soft open point in unbalanced active distribution networks," IEEE Transactions on Smart Grid, vol. 12, no. 1, pp. 587-598, 2021.

[11] H. Ji, C. Wang, P. Li, F. Ding, and J. Wu, "Robust operation of soft open points in active distribution networks with high penetration of photovoltaic integration," IEEE Transactions on Sustainable Energy, vol. 10, no. 1, pp. 280-289, 2019.

[12] T. Ding, Z. Wang, W. Jia, B. Chen, C. Chen, and M. Shahidehpour, "Multiperiod distribution system restoration with routing repair crews, mobile electric vehicles, and soft-open-point networked microgrids," IEEE Transactions on Smart Grid, vol. 11, no. 6, pp. 4795-4808, 2020.

[13] S. Sun, W. Cong, Y. Sheng, M. Chen, and Z. Wei, "Distributed power service restoration method of distribution network with soft open point," in Proceedings of the 2020 IEEE/IAS Industrial and Commercial Power System Asia, pp. 1616-1621, Weihai, China, July 2020.

[14] S. Ouyang, J. Liu, Y. Yang, X. Chen, S. Song, and H. Wu, "DC voltage control strategy of three-terminal medium-voltage power electronic transformer-based soft normally open points," IEEE Transactions on Industrial Electronics, vol. 67, no. 5, pp. 3684-3695, 2020.

[15] Y. Hou, Y. Xu, Z. Wang, X. Chen, and H. Cui, "Research on application of three-port SNOP based on dual closed-loop control in distribution network," in Proceedings of the 2017 IEEE International Conference on Smart Technologies and Management for Computing, Communication, Controls, Energy and Materials, pp. 389-395, Chennai, India, August 2017.

[16] B. Li, Y. Liang, G. Wang, H. Li, and J. Ding, "A control strategy for soft open points based on adaptive voltage droop outerloop control and sliding mode inner-loop control with feedback linearization," International Journal of Electrical Power \& Energy Systems, vol. 122, 2020.

[17] B. Yu, W. Song, J. Li, B. Li, and M. S. R. Saeed, "Improved finite control set model predictive current control for fivephase VSIs," IEEE Transactions on Power Electronics, vol. 36, no. 6, pp. 7038-7048, 2021.

[18] C. Zheng, T. Dragičević, Z. Zhang, J. Rodriguez, and F. Blaabjerg, "Model predictive control of LC-filtered voltage source inverters with optimal switching sequence," IEEE Transactions on Power Electronics, vol. 36, no. 3, pp. 34223436, 2021.

[19] A. Sarajian, C. Garcia, Q. Guan et al., "Overmodulation methods for modulated model predictive control and space vector modulation," IEEE Transactions on Power Electronics, vol. 36, no. 4, pp. 4549-4559, 2021. 
[20] H. Makhamreh, M. Trabelsi, O. Kükrer, and H. Abu-Rub, "A Lyapunov-based model predictive control design with reduced sensors for a PUC7 rectifier," IEEE Transactions on Industrial Electronics, vol. 68, no. 2, pp. 1139-1147, 2021.

[21] X. Zhang, G. Tan, T. Xia, and X. Wu, "Optimized switching finite control set model predictive control of NPC singlephase three-level rectifiers," IEEE Transactions on Industrial Electronics, vol. 35, no. 10, pp. 10097-10108, 2020.

[22] Y. Jin, X. Qian, J. Hou et al., "A novel sliding-discrete-controlset modulated model predictive control for modular multilevel converter," IEEE Access, vol. 9, pp. 10316-10327, 2021.

[23] W. Hu, C. Ruan, H. Nian, and D. Sun, "Zero-sequence current suppression strategy with common-mode voltage control for open-end winding PMSM drives with common DC bus," IEEE Transactions on Industrial Electronics, vol. 68, no. 6, pp. 4691-4702, 2021.

[24] B. Peng and G. Zhang, "Coordination control strategy for three-port SNOP based on FCS-MPC," The Journal of Engineering, vol. 2019, no. 16, pp. 1005-1010, 2019.

[25] W. Rui, S. Qiuye, M. Dazhong, and H. Xuguang, "Line impedance cooperative stability region identification method for grid-tied inverters under weak grids," IEEE Transactions on Smart Grid, vol. 11, no. 4, pp. 2856-2866, 2020.

[26] R. Wang, Q. Sun, W. Hu, Y. Li, D. Ma, and P. Wang, "SoCbased droop coefficients stability region analysis of the battery for stand-alone supply systems with constant power loads," IEEE Transactions on Power Electronics, vol. 36, no. 7, pp. 7866-7879, 2021. 